\title{
La participación ciudadana directa en el proceso de formación de los planes urbanísticos según la jurisprudencia
}

\author{
Enrique Orduña Prada
}

\begin{abstract}
Sumario: I. INTRODUCCIÓN. PLANTEAMIENTO Y DELIMITACIÓN DEL OBJETO DE ANÁLISIS. II. LA COMPETENCIA ESTATAL BÁSICA PARA QUE LA LEGISLACIÓN URBANÍSTICA GARANTICE, DE MANERA ABSTRACTA Y GENERAL, LA PARTICIPACIÓN CIUDADANA EN EL PROCEDIMIENTO DE ELABORACIÓN DEL PLANEAMIENTO URBANÍSTICO. III. LA PARTICIPACIÓN CIUDADANA EN LA FORMACIÓN DE LOS INSTRUMENTOS DE PLANEAMIENTO URBANÍSTICO Y SU CONEXIÓN CON EL «DERECHO A PARTICIPAR DIRECTAMENTE EN LOS ASUNTOS PÚBLICOS»EX ART. 23.1 CE. EN PARTICULAR, EL TRÁMITE DE INFORMACIÓN PÚBLICA Y LA CONSULTA POPULAR MUNICIPAL: III.1. La exclusión del contenido básico del art. 23.1 CE de la información pública en el procedimiento de elaboración del planeamiento; III.2. La consulta popular municipal como acto previo a la elaboración del plan y su posición privilegiada respecto de otras modalidades participativas. IV. LA PARTICIPACIÓN CIUDADANA PREVIA AL ACUERDO MUNICIPAL DE APROBACIÓN INICIAL DE LOS INSTRUMENTOS DE PLANEAMIENTO. LOS AVANCES Y TRABAJOS PRELIMINARES: IV.1. El Avance de planeamiento y el carácter potestativo de la información pública anterior a la aprobación inicial; IV.2. La intervención ciudadana en el trámite de exposición al público de los trabajos preparatorios del Plan. V. LA PARTICIPACIÓN CIUDADANA COMO MECANISMO DE CONTROL DE LA ACTIVIDAD DEL PLANIFICADOR. LAS «MODIFICACIONES SUSTANCIALES»DEL PLANEAMIENTO: CONCEPTO, DELIMITACIÓN Y EFECTOS: V.1. La participación ciudadana como título habilitante de la nueva información pública cuando se introducen «modificaciones sustanciales»; V.2. La delimitación jurisprudencial del concepto; V.3. Supuestos de nuevas determinaciones que se consideran «modificaciones sustanciales»; V.4. Efectos de la omisión del trámite de información pública en los casos en que se aprecia jurisdiccionalmente la existencia de esta clase de modificaciones. VI. CONCLUSIONES.
\end{abstract}

\section{INTRODUCCIÓN. PLANTEAMIENTO Y DELIMITACIÓN DEL OBJETO DE ANÁLISIS}

El procedimiento de elaboración y aprobación del planeamiento urbanístico, como es notorio, es un proceso bifásico en el que interviene en todo caso la Administración municipal y, eventualmente, la autonómica en los supuestos de tramitación de figuras de planeamiento general. Por su parte, la participación ciudadana en dicho procedimiento de elaboración de los distintos instrumentos de planeamiento urbanístico se articula, 
en el ámbito municipal, fundamentalmente a través de dos vías: una indirecta y otra directa ${ }^{1}$.

Por lo que se refiere a la vía indirecta de participación ciudadana, cabe entenderla como aquella en la que la intervención ciudadana en la elaboración del planeamiento urbanístico se hace efectiva mediante los órganos políticos y representativos de la voluntad popular municipal, cabalmente el Pleno y los concejales.

Esta modalidad participativa indirecta, propia de un sistema de democracia representativa en el que la organización institucional de la comunidad política local y su actividad encuentran su última legitimidad y justificación en que responden a la voluntad popular, ha sido destacada por el TS en relación con los límites de la intervención ciudadana en la formación de instrumentos de planeamiento. En este sentido, la jurisprudencia ha señalado que si bien la aprobación definitiva de aquellos instrumentos corresponde a las Corporaciones Locales y Comunidades Autónomas, «no [puede] ignorarse que las citadas Corporaciones están integradas por representantes generales de los vecinos, que participan también así («a través de representantes libremente elegidos en elecciones periódicas por sufragio universal») en los asuntos públicos, conforme al artículo 23 de la misma Norma Fundamental» ${ }^{2}$.

Planteamiento que, a nuestro modo de ver, refleja una de las características fundamentales de los Planes: éstos son el resultado de las diversas opciones políticas de quienes los elaboran y aprueban. Es decir, dentro de los límites preordenados por la legislación urbanística, los equipos de Gobierno municipal reflejan sus preferencias planificadoras de acuerdo con postulados ideológicos ${ }^{3}$. Afirmación, por otra parte, que viene a poner

1 Vid., F.J. ENÉriz OlAeCheA: «Artículo 6. Información y participación pública en el planeamiento y la gestión», en: VVAA, Comentarios a la Ley sobre Régimen del Suelo y Valoraciones. Ley 6/1998, de 13 de abril, Aranzadi, Pamplona, 1999, pp. 196 y ss.

${ }^{2}$ Cfr. STS de 23 de octubre de 1989, Ar. 7470, F.D. $5^{\circ}$ (F.J. Delgado Barrio, Revisión del PGOU de Cádiz). Por su parte, el TC ha puesto de manifiesto que si bien la participación ciudadana directa en el ámbito al que nos referimos, articulada a través del cauce de la información pública, opera como un factor coadyuvante de la legitimación popular del Plan, su legitimación democrática dimana directamente del hecho de haber sido aprobado por un Ayuntamiento elegido democráticamente (STC 164/2001, de 11 de julio, F.J. $6^{\circ}$ ). En definitiva, lo que se pretende poner de relieve es que en los planes concurre un plus de legitimidad democrática derivada de la participación directa e indirecta de los ciudadanos.

${ }^{3}$ La observación es de Luis MARTín ReBollo que, frente a la afirmación generalmente extendida de que la ejecución y gestión del Plan es una tarea política mientras que la función planificadora es eminentemente técnica, ha puesto de relieve que la situación es, precisamente, la inversa, en: «Presente y futuro del derecho urbanístico: una reflexión crítica», en T. Font i Llovet (dir.), Anuario del Gobierno Local. 2002, Institut de Dret Públic/Fundación Democracia y Gobierno Local, Barcelona, 2002, p. 51. 
de relieve la naturaleza eminentemente política de la actividad del gobierno local, superadora de la caracterización meramente burocrática de la actividad de gestión municipal que ejercen dichos órganos ${ }^{4}$.

Junto a la vía indirecta de participación a través de los representantes elegidos democráticamente, existe una vía directa de participación ciudadana que puede analizarse ${ }^{5}$ desde dos perspectivas diferentes. De una parte, desde el punto de vista del ciudadano, que se descompone a su vez en tres categorías: participación uti cives, participación uti dominus y participación uti gestor. Y de otra, desde el prisma de la Administración, en la que se distinguen la participación orgánica, funcional y cooperativa.

En apurada síntesis y sin entrar en mayores especulaciones dogmáticas, valga reseñar que la participación uti cives se predica de todos y cada uno de los ciudadanos en sentido genérico, con independencia de que sean titulares o no de derechos subjetivos o intereses legítimos -específicamente en la materia que nos ocupa, los propietarios de suelo-, que puedan verse afectados por la planificación urbanística. En definitiva, se trataría de la participación que puede ejercer cualquier ciudadano en su condición de destinatario inmediato de una concreta ordenación urbanística que va a incidir directamente en su calidad de vida y entorno.

Por su parte, la participación uti dominus se refiere no ya a la que pueden ejercer los ciudadanos considerados de modo abstracto como miembros de la comunidad política, sino en su condición de propietarios directamente afectados por la elaboración del Plan. Esta modalidad participativa ha sido articulada por el derecho positivo tradicionalmente a través de figuras como los proyectos de reparcelación, la ejecución directa de la urbanización por los propietarios, la Junta de Compensación o la constitución de asociaciones administrativas de propietarios en el sistema de cooperación.

\footnotetext{
${ }^{4}$ A fin de cuentas se trata de poner de relieve que la autonomía local no es meramente una autonomía administrativa, sino que posee una fuerte naturaleza política, tal y como han destacado, entre otros, E. AJA: «Configuración constitucional de la autonomía local», en: Informe sobre el Gobierno Local, MAP/Fundación Carles Pi i Sunyer, Madrid, 1992, p. 41-66; J. GARCía MoRILLO: La configuración constitucional de la autonomía local, Marcial Pons, Madrid, 1998, 102 p.; y, J. GARCíA RocA: «El concepto actual de autonomía local según el bloque de la constitucionalidad», REALA, n. ${ }^{\circ} 282,2000$, p. $23-70$.

${ }^{5}$ En este punto seguimos en la exposición los conocidos trabajos de E. GARCía de ENTERRíA: «Los principios de la organización del urbanismo», en: Libro Homenaje a Manuel García Pelayo, Tomo I, Universidad Central de Venezuela/Facultad de Ciencias Jurídicas y Políticas, Caracas, 1980, pp. 365-398; ibidem, «Principios y modalidades de la participación ciudadana en la vida administrativa», en: R. GómEz-Ferrer Morant (coord.), Libro Homenaje al profesor José Luis Villar Palasí, Civitas, Madrid, 1989, pp. 437-452; y junto con T.R. FerNÁNDEZ, en: Curso de Derecho Administrativo, II, $7^{\mathrm{a}}$ ed., Civitas, Madrid, 2000, pp. 85-96.
} 
En último término, la participación uti gestor tiene lugar cuando los ciudadanos, propietarios de un ámbito determinado, asumen la función de gestores en la formación o ejecución de planes de urbanismo. Este sería, a título de ejemplo, el supuesto de la iniciativa privada para redactar instrumentos de ordenación urbanística.

De otra parte, desde la perspectiva de la Administración las modalidades participativas en que se puede ordenar la actuación de los ciudadanos son, en primer lugar, la denominada participación orgánica, que se concibe como aquella que supone la integración de los ciudadanos en órganos formalizados, permanentes o no, de la Administración por su condición de tales, esto es, sin que concurran en ellos especiales circunstancias subjetivas. En segundo término, la participación funcional en la que a diferencia de la anterior no existe dicha integración ciudadana en los órganos de la Administración, ejercitando las particulares funciones públicas y, por ello, colaborando en las tareas propias de la Administración. Este sería el caso, por ejemplo, de la participación en informaciones públicas, las peticiones y propuestas, el ejercicio judicial de acciones populares, etc. Por último, aparece la participación cooperativa que se comprende como una cooperación facilitada al margen del aparato administrativo, pero que implica una específica colaboración voluntaria en los programas promovidos por la Administración.

Esta sucinta exposición de las diferentes modalidades participativas nos proporciona dos criterios fundamentales para delimitar el objeto del presente trabajo. En efecto, en primer lugar debemos hacer notar que en las páginas que siguen a continuación vamos a referirnos de manera preferente al tratamiento que la jurisprudencia ha conferido a la participación directa de los ciudadanos en la formación de los planes en su condición de sujetos integrantes de la comunidad política local, bien de manera individual, bien a través de órganos o entidades asociativas voluntarias. Quedan, pues, fuera de nuestro alcance otras modalidades participativas ciudadanas, singularmente en lo que respecta a la ejecución del planeamiento y a la fiscalización de la observancia de la legalidad urbanística.

La segunda cuestión hace referencia a los instrumentos en que se sustancia formalmente esa participación ciudadana directa, porque la legislación urbanística estatal y autonómica la han circunscrito básicamente al trámite de información pública que se abre tras la aprobación inicial de los diferentes instrumentos de ordenación urbanística. En efecto, a pesar de que las diversas Leyes de Urbanismo autonómicas contienen expresas apelaciones encaminadas a fomentar y asegurar tal clase de participación por parte de las Administraciones competentes, los términos abstractos e 
imprecisos en los que se conciben, ofrecen como resultado que únicamente tiene fuerza vinculante para los Tribunales el reiterado trámite de información pública ${ }^{6}$. A este mecanismo, que puede ser ejercido por cualquier ciudadano, hay que añadir el instituto de la consulta popular municipal regulada con carácter básico en la LrBRL que opera, asimismo, como un instrumento de participación ciudadana en la elaboración de planes urbanísticos, aunque, como es sabido, sin carácter vinculante en cuanto a su resultado.

Resta, por lo demás, formular dos advertencias preliminares en atención a la jurisprudencia que se ha manejado para la confección del presente trabajo. En primer lugar, y en estrecha conexión con lo expuesto en el párrafo anterior, debemos hacer notar que las Sentencias tomadas en consideración, tanto del TS como de los TSJ de las Comunidades Autónomas, tienen por objeto de análisis fundamental preceptos del Real Decreto 2159/1978, de 23 de junio, por el que se aprueba el reglamento de Planeamiento (desde ahora, RPU) invocados por las partes en los correspondientes procesos jurisdiccionales ${ }^{7}$. Reglamento que, como es notorio, opera como derecho supletorio del de las Comunidades Autónomas en el caso de que éstas no hayan legislado sobre la materia tal y como se infiere del fallo de la STC 61/1997, de 20 de marzo. De modo que, en principio, podemos entender que la jurisprudencia examinada mantiene su vigencia y eficacia, salvo en el caso de aquellas Comunidades Autónomas que hayan dictado su propio Reglamento de Planeamiento en desarrollo de la correspondiente ley urbanística autonómica ${ }^{8}$.

La segunda advertencia que debemos reseñar consiste en que, a pesar de que tanto la doctrina como la jurisprudencia se han encargado de recordar reiteradamente que la participación ciudadana directa en la elabora-

\footnotetext{
${ }^{6}$ Sin perjuicio, claro está, de que en la mayor parte de las ocasiones los Ayuntamientos que confeccionan sus planes de urbanismo arbitren otras fórmulas participativas que se deben, más que a prescripciones legales concretas, al interés de los equipos redactores, técnicos municipales y representantes políticos. Pueden verse experiencias de esta naturaleza en F. PeÑa FernándeZ y A. PeralTA: «La praxis en las alteraciones del planeamiento», en: Jornadas de Derecho Urbanistico. Estudios de derecho urbanístico I (Las alteraciones del Planeamiento), CEMCI, Granada, 1983, pp. 5572; A. Enguita PueBla: «La participación ciudadana en el urbanismo», Revista de Derecho Urbanístico, n. ${ }^{\circ}$ 93, 1985, pp. 63-80; y, J.J. TRAPERO: «La participación ciudadana en el planeamiento: la construcción y la gestión de los asentamientos urbanos», Ciudad y Territorio, n. ${ }^{\circ}$ 53, pp. 73-88.

${ }^{7}$ Básicamente los arts. 115, 116, 125, 130 y 132 RPU.

${ }^{8}$ Este sería el caso, por ejemplo, de los Decretos 22/2004, de 29 de enero, por el que se aprueba el Reglamento de Urbanismo de Castilla y León, que unifica en un único texto las materias de planeamiento, gestión y disciplina urbanística, y 248/2004, de 14 de septiembre, por el que se aprueba el Reglamento de Planeamiento de la Ley 2/1998, de 4 de junio, de Ordenación del Territorio y de la Actividad Urbanística de Castilla-La Mancha.
} 
ción de los planes, a través de los conocidos instrumentos de la información pública y consulta popular, corresponde a cualquier ciudadano sin necesidad de que concurra en ellos circunstancia específica alguna, la realidad no se ajusta a este aserto. En efecto, la jurisprudencia que se ha manejado pone de relieve que son mayoritariamente los propietarios de terrenos o inmuebles afectados por la concreta ordenación urbanística que propone el plan quienes formulan las alegaciones en la fase de información pública $\mathrm{y}$, posteriormente, continúan con sus pretensiones en los correspondientes procesos jurisdiccionales. Sólo en un número mínimo aparecen entidades asociativas voluntarias o representativas de intereses profesionales como partes en el proceso contencioso-administrativo, pero en prácticamente ningún caso figuran ciudadanos particulares que carezcan de la condición de propietarios ${ }^{9}$.

De acuerdo con los criterios y advertencias acabados de exponer, corresponde señalar que la sistemática empleada en la elaboración del presente análisis se ordena de acuerdo con la siguiente estructura. En primer lugar, nos referiremos a la jurisprudencia constitucional -SSTC 61/1997, de 20 de marzo y 164/2001, de 11 de julio- que atribuye al Estado la competencia básica para fijar en su legislación urbanística general una garantía abstracta en orden a asegurar la participación ciudadana en los procesos de formación y gestión del planeamiento. Tal y como tendremos ocasión de ver en su momento, según el TC el Estado, a pesar de carecer de competencias legislativas en materia de planeamiento urbanístico, puede, paradójicamente, establecer una cláusula de garantía a fin de que la legislación urbanística autonómica asegure la participación ciudadana en el proceso de formación y gestión de los planes urbanísticos.

En segundo término, nos detendremos en el examen de la jurisprudencia relativa a la pretendida conexión de la participación ciudadana en la elaboración de los planes con el derecho fundamental a participar directamente en los asuntos públicos consagrado en el art. 23.1 CE en dos manifestaciones concretas: el trámite de información pública y la consulta

\footnotetext{
${ }^{9}$ Con carácter general podemos ajustarnos al siguiente esquema: a) en la mayor parte de los casos son los particulares propietarios quienes accionan el correspondiente procedimiento contenciosoadministrativo; $b$ ) en número inferior aparecen entidades mercantiles en sus diversas modalidades recurriendo el plan urbanístico aprobado; $\mathrm{y}, c$ ) con carácter residual aparecen, bien entidades representativas de intereses económicos y profesionales, [Confederación de Asociaciones de Empresarios, STS de 3 de mayo de 1996, Ar. 3848 (P.J. YAGÜE GIL, PGOU de Muro); Cámaras Agrarias, STS de 12 de noviembre de 1998, Ar. 9597 (J. RoDRíGUEZ-ZAPATA PGOU de Vilassar de Mar); Colegio Oficial de Arquitectos, SSTS de 13 de octubre de 1988, Ar. 8216 (J. GARCÍA EstaRTús) y de 10 de octubre de 1989, Ar. 7351 (J. GarCía Ramos IturRalde, Normas Subsidiarias de Ses Salines)], bien entidades asociativas de base voluntaria, [Unión de Iglesias Cristianas Adventistas del Séptimo Día de España, STS de 29 de diciembre de 1989].
} 
popular municipal. Valga apuntar por ahora que, si bien la jurisprudencia ordinaria y constitucional han fijado reiteradamente el fundamento constitucional de la participación ciudadana en el proceso de elaboración del planeamiento en los arts. 9.2 y 105.a), por el contrario, han descartado de plano que la omisión del trámite de información pública pueda considerarse una violación del derecho fundamental precitado, generando mayores dudas cuando de lo que se trata es del caso de las consultas populares.

A continuación, y siguiendo el iter procedimental de confección de los planes urbanísticos ${ }^{10}$, nos dedicaremos al análisis del sentido que la jurisprudencia ha conferido a la participación ciudadana en la fase de actuaciones previas o preparatoria del futuro plan. En particular, nos estamos refiriendo a dos modalidades participativas que se concretan en la potestad de abrir un periodo de información pública del Avance del plan propuesto y a la exposición pública de los trabajos preparatorios o preliminares, en ambos casos con la finalidad de que los ciudadanos formulen sugerencias, indicaciones o alternativas.

En cuarto y último lugar, prestaremos atención a una de las funciones de la participación ciudadana en el contexto que nos ocupa y que la jurisprudencia ha perfilado con mayor detalle y profusión. Se trata de la función de control de la actividad de planeamiento que ejercen los ciudadanos mediante la garantía de la reiteración del trámite de información pública en aquellos supuestos en que, por el órgano administrativo competente en materia urbanística, se incorporan las denominadas «modificaciones sustanciales» operadas con motivo de las aprobaciones inicial, provisional y definitiva.

En este contexto tendremos ocasión de examinar diferentes cuestiones como son: la consideración de la participación ciudadana como fundamento de la necesidad de apertura de un nuevo periodo de información pública en caso de introducirse modificaciones sustanciales; la configuración de tales modificaciones como concepto jurídico indeterminado y su aplicación práctica para determinar los supuestos en que las mismas se

\footnotetext{
${ }^{10}$ En este sentido, P. Morillas SÁnCHEZ ha distinguido las siguientes fases de participación ciudadana en el proceso de elaboración de los planes: a) elaboración de encuestas a la población con la finalidad de conocer las opiniones populares en el momento de elaboración y formación del Plan; b) conocimiento de los proyectos e intenciones de los colectivos sociales a través de su participación en reuniones, comités de expertos, etc; $c$ ) exposición de los trabajos preliminares toda vez que se haya elaborado el Avance del plan; $d$ ) el periodo de información pública que se abre tras la aprobación inicial por el pleno municipal; $\mathrm{y}, e$ ) tras la aprobación definitiva, cualquier ciudadano puede impugnar cualquier determinación del plan; vid., «El planeamiento urbanístico», en: J. A. LÓPEZ Pellicer (coord.), Derecho Urbanístico Práctico. Autonómico y estatal supletorio. Expedientes, documentación y normativa, I, El Consultor, Madrid, 2001, pp. 45-46.
} 
producen; y, por último, los efectos que produce la ausencia de información pública cuando se introducen las reiteradas modificaciones.

\section{LA COMPETENCIA ESTATAL BÁSICA PARA QUE LA LEGISLACIÓN URBANÍSTICA GARANTICE, DE MANERA ABSTRACTA Y GENERAL, LA PARTICIPACIÓN CIUDADANA EN EL PROCEDIMIENTO DE ELABORACIÓN DEL PLANEAMIENTO URBANÍSTICO}

La legislación urbanística ha concebido tradicionalmente la participación ciudadana en la elaboración de los diferentes instrumentos de planeamiento de acuerdo con dos presupuestos. De una parte, desde la LS/1956 se habilita la intervención de los ciudadanos en el procedimiento administrativo de formación de tales planes a través del trámite de información pública posterior a la aprobación inicial del planeamiento, mediante la formulación de alegaciones. Se trata de una modalidad participativa concreta que deriva del carácter normativo del planeamiento urbanístico, esto es, de su condición de disposición administrativa de carácter general. Y, de otra parte, mediante la introducción a partir de 1976 de un deber genérico, ciertamente difuso en cuanto a su plasmación práctica, que corresponde bien a los «órganos competentes»-art. 4.2 TRLS/1976-, bien a «las Administraciones urbanísticas competentes» -art. 4.4 TRLS/1992- de «asegurar la mayor participación de los interesados y en particular los derechos de iniciativa e información» en la formulación, tramitación y gestión del planeamiento urbanístico ${ }^{11}$.

Este esquema legal se ha visto alterado, en cuanto a la competencia legislativa, desde la conocida STC 61/1997, de 20 de marzo, en la medida en que a partir de la misma el Estado carece de competencias normativas en materia de planeamiento urbanístico y, por lo tanto, para fijar técnicas o modalidades participativas concretas y específicas en el procedimiento de planificación urbanística. Sin embargo, ha sido el propio TC el encargado de delimitar gradualmente el carácter básico de la competencia estatal para que la legislación urbanística garantice de forma abstracta y

\footnotetext{
${ }^{11}$ Este sería a grandes rasgos el planteamiento que se deduce de la legislación urbanística desde 1956. Sobre la escasa operatividad del trámite de información pública que preveía la LS/1956 como factor de legitimación del planeamiento y las circunstancias que motivaron la redacción del art. 4.2 TRLS/1976, pueden verse L. PAREJo Alfonso: Derecho Urbanistico. Instituciones básicas, Edic. Ciudad Argentina, Buenos Aires, 1986, pp. 358-359 y T.R. Fernández Rodríguez: Manual de Derecho Urbanistico, $16^{\mathrm{a}}$ ed., El Consultor, Madrid, 2001, pp. 84-86.
} 
genérica la participación ciudadana en el procedimiento de elaboración del planeamiento, de manera indirecta en la precitada STC 61/1997, de 20 de marzo y, entrando en el fondo del asunto en la STC 164/2001, de 11 de julio.

Por lo que respecta a la primera de las Sentencias indicadas, a los efectos que ahora interesan, hay que recordar que, entre los numerosos preceptos del TRLS/1992 que fueron recurridos por las Comunidades Autónomas, la Generalidad de Cataluña impugnó el art. 113.2 al entender que imponía trámites que debían ser decididos desde la competencia urbanística autonómica. Este precepto, relativo a los denominados Planes Directores Territoriales de Coordinación ${ }^{12}$, regulaba los trámites de información pública ciudadana y de audiencia a la Administración del Estado, en los aspectos de su competencia, y a las Entidades Locales afectadas en el procedimiento de elaboración de los indicados Planes Directores.

En lo que ahora importa, el TC salva la constitucionalidad de la previsión normativa estatal y su carácter básico, al reconducir el trámite de información pública ciudadana a la competencia estatal sobre las bases del régimen jurídico de las Administraciones Públicas en los siguientes términos: «En todo caso, y ello es lo relevante, el Estado ostenta competencias exclusivas para dictar normas de procedimiento administrativo común (art. 149.1.18 $\mathrm{CE}$ ), entre las que se incluyen aquellas garantías o derechos procedimentales que hayan de respetarse para la formulación de las disposiciones administrativas que afecten a los ciudadanos. Aunque el legislador estatal podría haber dispuesto con carácter general y respecto de toda forma de planeamiento urbanístico la obligatoriedad de la garantía de la información pública al amparo del art. $149.1 .18^{\circ} \mathrm{CE}$, y no en relación con un concreto instrumento (el Plan Director) -cuya misma existencia depende de cada Comunidad Autónoma-, parece claro que la regulación que lleva a cabo el artículo 113.2 TRLS se enmarca en la competencia estatal ex artículo $149.1 .18^{\circ} \mathrm{CE}$ y es respetuosa con la materia urbanística, cuando no hace sino asegurar la existencia del trámite de información pública» (F.J. 25.c) $)^{13}$.

A pesar de que el extenso párrafo transcrito se refiere exclusivamente a la participación ciudadana en un concreto instrumento de planeamiento - los referidos Planes Directores Territoriales de Coordinación-, podemos formular alguna observación general que se deduce de su tenor literal. En

\footnotetext{
12 Planes que tenían por objeto la ordenación de la totalidad o parte del territorio de una Comunidad Autónoma, de acuerdo con los arts. 65.2, 68 y 69 TRLS/1992.

13 La cursiva es nuestra.
} 
este sentido, hay que partir de la idea que, en la actualidad, no parece generar controversia alguna afirmar la naturaleza normativa del planeamiento urbanístico, carácter reconocido y reiterado por la doctrina y la jurisprudencia en numerosas ocasiones ${ }^{14}$. La naturaleza reglamentaria del Plan implica, por lo tanto, que se trata de una disposición administrativa de carácter general, sometida a un procedimiento de elaboración en el que «la participación de los ciudadanos resulta insoslayable a tenor del art. 105.a) CE» ${ }^{15}$, materializándose formalmente dicha intervención a través de la garantía de la audiencia de los ciudadanos e información pública en tal procedimiento. Esta circunstancia constituye el motivo por el que la doctrina ha puesto de relieve que el contenido del reiterado art. 105.a) CE se configura como una garantía constitucional que cumple una triple función vinculada al principio de Estado Social y Democrático de Derecho: primera, en cuanto tiende a proteger los derechos e intereses de los particulares potencialmente afectados por la disposición administrativa de que se trate; segunda, porque coadyuva al acierto y eficacia de la concreta norma administrativa, dotando de contenido sustantivo al postulado de eficacia y eficiencia propio del Estado social; tercera, y última, por reforzar la legitimación democrática de la norma de que se trata ${ }^{16}$.

Lo expuesto adquiere mayor trascendencia, cuando de lo que se trata es de la participación ciudadana en el procedimiento de elaboración del planeamiento urbanístico por dos motivos. En primer lugar, porque en dicho procedimiento se ven afectados y condicionados primariamente el contenido del derecho de propiedad y el desarrollo de la ciudad ${ }^{17}$. Y, en segundo término, en estrecha conexión con lo anterior, porque los procesos de ordenación urbanística y su posterior gestión van referidos a un interés general, que trasciende el propio de quienes pueden entenderse directamente afectados por los mismos - primariamente, los propietarios-, que implica la nece-

\footnotetext{
${ }_{14} \mathrm{Al}$ respecto, entre otros, J.M TRAYTER JIMÉNEZ: El control del planeamiento urbanístico, Civitas, Madrid, 1996, en especial pp. 54 y ss, y la bibliografía y jurisprudencia que allí se cita.

15 Entre otras, SSTS de 14 de noviembre de 1990, Ar. 8930, F.D $3^{\circ}$ (P. Esteban Álamo, PGOU de L'Escala); y de 2 de octubre de 1991, Ar. 7717, FF.DD. $1^{\circ}$ y $2^{\circ}$ (J. GARCía-RAmos ItURRALDE, PGOU de L'Escala).

${ }^{16}$ Sobre los tres fines que cumple el art. 105.a) CE véase J.R. PARAdA VÁzQueZ y M. Bacigalupo SAGGESE: «Artículo 105. Audiencia del ciudadano en procedimientos administrativos y acceso de los ciudadanos a los archivos y registros administrativos», en: O. AlzaGA (dir.), Comentarios a la Constitución Española de 1978, Tomo VIII, Edersa/Cortes Generales, Madrid, 1998, pp. 525-534.

17 La STC 164/2001, de 11 de julio ha puesto de relieve que cuando la LRSV/1998 emplea la expresión «planeamiento urbanístico» está haciendo referencia al «instrumento de ordenación que determina el haz de facultades urbanísticas sobre cada terreno que haga compatible el disfrute de las facultades urbanizadoras y edificatorias con la estructura y singularidades de cada ciudad» [F.J. 6.a)].
} 
sidad de garantizar a toda la colectividad su participación en la formulación de aquéllos. En definitiva, el ciudadano no sólo interviene en defensa de sus propios intereses particulares, sino también para tomar parte en la adopción de decisiones que afectan a la comunidad en la que vive ${ }^{18}$.

De modo que es a la luz de las consideraciones acabadas de exponer el contexto en el que, a nuestro modo de ver, hay que delimitar la hermenéutica constitucional que lleva a cabo la reiterada STC 61/1997, que, sin mencionarlo expresamente, pretende consagrar la garantía de un tratamiento común y unitario del ciudadano en todo el territorio estatal cuando se ve afectado por la formulación del plan ${ }^{19}$. En otras palabras, busca garantizar que los ciudadanos reciban un trato igual por cualquiera de las Administraciones urbanísticas que formulan un plan mediante la salvaguarda de la garantía de su participación a través del trámite de audiencia e información pública. Sólo así se comprende, a nuestro juicio, que el TC integre en el contenido de la competencia estatal sobre procedimiento administrativo común el precitado trámite de información pública a los ciudadanos en el procedimiento de elaboración de un específico instrumento de planeamiento, permitiendo, al tiempo, que pueda hacerse extensivo a cualesquiera otros instrumentos planificadores.

De acuerdo con la doctrina establecida por la STC 61/1997 y los antecedentes legislativos inmediatos, el art. 6.1 LRSV/1998 establece en su inciso primero que «la legislación urbanística garantizará la participación pública en los procesos de planeamiento y de gestión». Previsión legal que se extiende a cualesquiera instrumentos de ordenación y que se formula con carácter abstracto sin enumerar técnicas concretas en las que haya de instrumentalizarse esa participación. Facultad que se remite, por lo tanto, a la legislación urbanística autonómica que será la encargada de fijar y precisar tales técnicas, de acuerdo con el clásico esquema bases del Estado-desarrollo autonómico.

La segunda oportunidad en la que el TC ha tenido ocasión de pronunciarse sobre la materia que nos ocupa es la STC 164/2001, de 11 de julio,

\footnotetext{
18 Tal y como puso de relieve en fecha temprana S. MuÑOZ MACHADO: «Las concepciones del derecho administrativo y la idea de participación en la Administración», RAP, n. ${ }^{\circ}$ 84, 1977, p. 532.

19 L. PAREJo ha destacado el discutible fundamento en el art. 149.1.18 ${ }^{\mathrm{a}} \mathrm{CE}$ de la participación pública en el planeamiento, por relación a la garantía de un tratamiento común del ciudadano, vid.: «El urbanismo en la encrucijada: la elección del modelo legislativo general idóneo para una política de ordenación territorial y urbanística acorde con el orden constitucional», en: L. PAREJO (coord.), El urbanismo hoy. Reflexiones a propósito de la STC 61/1997 y el proyecto de nueva Ley estatal, Instituto Pacual Madoz de Ordenación del Territorio, Urbanismo y Medio Ambiente, Madrid, 1997, pp. 241-242.
} 
que resuelve diversos recursos de inconstitucionalidad, acumulados, formulados contra la LRSV/1998 por el Parlamento de Navarra, el Consejo de Gobierno de la Junta de Extremadura y ochenta y cuatro Diputados de los Grupos Parlamentarios Socialista, Federal de Izquierda Unida y Mixto. Entre los preceptos impugnados por estos últimos se encuentra el precitado art. $6 \mathrm{LRSV} / 1998$ al entender los recurrentes, de una parte, que la participación pública no se ampara en ningún título competencial del Estado, ni siquiera en el art. 149.1.18 $\mathrm{CE}$, en la medida que este precepto se refiere exclusivamente al procedimiento administrativo común y no a procedimientos administrativos sectoriales como es el caso del urbanismo; y, de otra, que la regulación que efectúa el precepto impugnado predetermina la existencia de ciertas técnicas urbanísticas, condicionando así el ejercicio de las competencias autonómicas sobre el urbanismo.

Para delimitar la competencia básica que corresponde al Estado a fin de garantizar la participación ciudadana en el procedimiento de elaboración del planeamiento, el TC reitera argumentos ya empleados en la anterior sentencia comentada y, al tiempo, determina qué ha de entenderse por participación pública en el proceso urbanístico de planeamiento.

De manera que, «la «participación pública» -señala el TC- que impone el artículo 6.1 LRSV ha de contraponerse a la «participación privada» regulada en el artículo 4 LRSV. Se trata ahora de la participación ciudadana, no del derecho de los propietarios y empresarios a la participación e iniciativa urbanísticas. [...] Tanto el mandato de participación pública como los derechos informativos (de acceso y prestacional) son reconducibles a la competencia estatal sobre bases del régimen jurídico de las Administraciones públicas y procedimiento administrativo común (art. 149.1.18 CE), sin simultánea invasión de las competencias urbanísticas autonómicas» (F.J. 11 ${ }^{\circ}$ ).

Sentado lo anterior, el razonamiento del TC se construye sobre tres argumentos para no apreciar vicio de inconstitucionalidad alguno en el precepto impugnado. En primer lugar, el Alto Tribunal entiende que el carácter eminentemente sectorial del artículo 6 LRSV/1998 no sirve, por sí sólo, para cuestionar la competencia estatal sobre bases del régimen jurídico de las Administraciones Públicas y procedimiento administrativo común. Esto es, a pesar de que son las Comunidades Autónomas las que ostentan competencia legislativa para regular el procedimiento administrativo de aprobación de planes urbanísticos, su naturaleza sectorial no puede imponerse a la competencia general de la que es titular el Estado para fijar las bases de aplicación común al procedimiento administrativo. 
En segundo lugar, y en íntima conexión con el argumento anterior, afirma el TC que los dos párrafos del meritado artículo 6 regulan las relaciones entre los ciudadanos y las Administraciones Públicas, ámbito normativo donde la competencia básica del Estado es incuestionable, porque el objetivo último de las bases contenidas en el art. $149.1 .18^{\mathrm{a}}$ es el de garantizar a los administrados un tratamiento común ante ellas, tal y como puso de manifiesto en el F.J. $3^{\circ}$ de la STC 50/1999, de 6 de abril.

En última instancia, el TC pone de relieve cómo el carácter abstracto del art. 6 LRSV/1998 no supone la imposición de técnica urbanística alguna a las Comunidades Autónomas ni predetermina un único modelo de participación e información ciudadanas, dejando un amplio margen de desarrollo legislativo a éstas para que puedan fijar técnicas o modalidades participativas concretas.

En definitiva, a tenor de la jurisprudencia del TC, el Estado es titular de la competencia básica para fijar en la legislación estatal una garantía genérica a fin de que las leyes urbanísticas autonómicas aseguren la participación de la comunidad vecinal en la formación de los instrumentos de ordenación urbanística, en tanto y cuanto dicha intervención ciudadana se configura como una garantía de sus derechos e intereses, que encuentra fundamento constitucional en el art. 149.1.18 ${ }^{\mathrm{a}}$. Y, a mayor abundamiento, cabe sostener que la omisión por parte de las leyes autonómicas del reconocimiento de la participación ciudadana en el referido procedimiento administrativo implicaría la inconstitucionalidad de la norma de que se trate.

De acuerdo con estas prescripciones jurisprudenciales, la legislación urbanística autonómica parte del genérico reconocimiento del derecho de participación de los ciudadanos en la «formulación, tramitación y gestión del planeamiento urbanístico», reproduciendo en similares términos el tenor del precitado art. 4.2 TR/1976, y configurando tal derecho bien como un principio que informa y preside toda actuación pública y privada en relación con la ordenación urbanística -v.g. Canarias y Madrid-, bien como una finalidad de la actividad administrativa en materia urbanística-Región de Murcia-.

A partir de este presupuesto genérico es posible distinguir algunas especialidades autonómicas que, de modo sucinto, pueden ordenarse en tres bloques $^{20}$. En primer lugar, las Comunidades Autónomas que se limitan,

\footnotetext{
20 Sin perjuicio de la expresa previsión legislativa de la apertura de un periodo de información pública tras las aprobaciones inicial y provisional en la formulación de las diferentes figuras de planeamiento general y de desarrollo que contienen todas las Leyes autonómicas.
} 
sin más, a reproducir con mayor o menor literalidad el reiterado art. 4.2 TRLS/1976 acabado de señalar -Galicia, La Rioja, Aragón, Castilla y León, Murcia, Madrid y Cataluña- ${ }^{21}$; en segundo término, aquellas Comunidades Autónomas que específicamente reconocen el derecho de los ciudadanos a formular alegaciones durante el periodo de información pública de los instrumentos de planeamiento como mecanismo de participación en su confección -Asturias, Canarias, Castilla-La Mancha, Extremadura y Andalucía-22; y, en último término, la Comunidad Foral de Navarra que previene expresamente la cautela de asegurar la apertura de un periodo de información pública mínima de veinte días respecto de la elaboración de cualquier instrumento de ordenación urbanística, previo a su aprobación definitiva ${ }^{23}$.

Como se observa de lo expuesto hasta ahora, el Estado es titular de la competencia básica para fijar en su legislación la garantía de la participación ciudadana en el procedimiento de elaboración de los planes urbanísticos, mediante una fórmula genérica y abstracta, mientras que su desarrollo y concreción normativa posterior corresponden a las Comunidades Autónomas. Hay que advertir cómo la Ley estatal se refiere a «la legislación urbanística» y no a los «órganos competentes» o «las Administraciones urbanísticas», fórmulas tradicionales que había empleado nuestro derecho positivo desde 1976, trasladando así la obligación legislativa de fijar mecanismos concretos de participación a las Leyes de las Comunidades Autónomas. De modo que, ante la inacción legislativa autonómica en este concreto aspecto ${ }^{24}$, se abre un amplio ámbito de normación a los

${ }^{21}$ Arts. 4 de la Ley 9/2002, de 30 de diciembre, de Ordenación Urbanística y Protección del Medio Rural de Galicia; 4 de la Ley 10/1998, de 2 de julio, de Ordenación del Territorio y Urbanismo de La Rioja; 7 de la Ley 5/1999, de 25 de marzo, Urbanística de Aragón; 6 de la Ley 5/1999, de 8 de abril, de Urbanismo de Castilla y León; 9 de la Ley 1/2001, de 24 de abril, del Suelo de la Región de Murcia; 3.1 de la Ley 9/2001, de 17 de julio, del Suelo de la Comunidad de Madrid; y 8.1 de la Ley $2 / 2002$, de 14 de marzo, de Urbanismo de Cataluña.

${ }^{22}$ Arts. 7.2 del Decreto Legislativo 1/2004, de 22 de abril, por el que se aprueba el Texto Refundido de las disposiciones legales vigentes en materia de Ordenación del Territorio y Urbanismo del Principado de Asturias; 8 del Decreto Legislativo 1/2000, de 8 de mayo, por el que se aprueba el Texto Refundido de las Leyes de Ordenación del Territorio de Canarias y de Espacios Naturales de Canarias; 8 del Decreto Legislativo 1/2004, de 28 de diciembre, por el que se aprueba el Texto Refundido de la Ley de Ordenación del Territorio y de la Actividad Urbanística de Castilla-La Mancha; 7 de la Ley 15/2001, de 14 de diciembre, del Suelo y Ordenación Territorial de Extremadura; y 6.1 de la Ley 7/2002, de 17 de diciembre, de Ordenación Urbanística de Andalucía.

${ }^{23}$ Art. 7de la Ley Foral 35/2002, de 20 de diciembre, de Ordenación del Territorio y Urbanismo.

${ }^{24}$ El déficit legislativo de mecanismos participativos había sido ya resaltado por la STS de 10 de mayo de 1990, Ar. 4059, F.D. $4^{\circ}$ de la Sentencia apelada (P. Esteban Álamo, Revisión del PGOU de Pinto), al advertir que, «la participación ciudadana en la elaboración del planeamiento se ha revelado como uno de los aspectos más desatendidos e insatisfactoriamente tratados por nuestra legislación 
Ayuntamientos para, fundamentalmente a través de los Reglamentos Orgánicos de los diferentes órganos participativos previstos en la LrBRL, establecer en virtud de su potestad de autoorganización, mecanismos específicos de participación social complementarios del clásico instrumento de la información pública, ya sean manifestación de una participación asociada ${ }^{25}, \mathrm{o}$ individual ${ }^{26}$.

\section{LA PARTICIPACIÓN CIUDADANA EN LA FORMACIÓN DE LOS INSTRUMENTOS DE PLANEAMIENTO URBANÍSTICO Y SU CONEXIÓN CON EL «DERECHO A PARTICIPAR DIRECTAMENTE EN LOS ASUNTOS PÚBLICOS» EX ART. 23.1 CE. EN PARTICULAR, EL TRÁMITE DE INFORMACIÓN PÚBLICA Y LA CONSULTA POPULAR MUNICIPAL}

La participación ciudadana en el proceso de elaboración de los diferentes instrumentos de ordenación urbana se ha circunscrito tradicionalmente por el derecho positivo a la apertura, tras su aprobación inicial y provisional, de un periodo de información pública a través del cual cualquier ciudadano, tenga o no un interés directo, puede materializar formalmente alegaciones al modelo de planeamiento propuesto. No obstante, la intervención ciudadana no se agota con ese trámite procedi-

\footnotetext{
urbanística». Recuérdese, con carácter general, cómo G. Ariño Ortiz destacaba en 1978 la necesidad de que la participación ciudadana en el aparato administrativo no podía ser algo simbólico y ocasional, sino «algo estable y permanente», institucionalizado a través de la reforma de una pléyade de Leyes sustantivas; vid.: «Democracia y Administración (Notas sobre participación ciudadana en los procesos de decisión)», en: VVAA, Estudios sobre el proyecto de Constitución, CEC, Madrid, 1978, 145-175. Asimismo, un análisis sobre la participación y su reflejo en la legislación puede verse en A. PÉREZ Moreno: «Crisis de la participación administrativa», RAP, n. ${ }^{\circ} 119,1989$, pp. 91-132.

${ }^{25}$ Singularmente a través de los denominados Consejos Sociales de la Ciudad previstos en el art. 131 LrBRL, de creación obligatoria en los municipios a los que resulte de aplicación el régimen del Título X de la LrBRL, integrados por representantes de las organizaciones económicas, sociales, profesionales y de vecinos más representativas del correspondiente municipio, y entre cuyas funciones mínimas le corresponde la emisión de informes, estudios y propuestas en materia de desarrollo económico local, planificación estratégica de la ciudad y grandes proyectos urbanos. Valga reseñar que esta posibilidad no era desconocida para los municipios españoles, como lo demuestra la experiencia de los denominados «Consejos de Ciudad» que tienen atribuidas similares funciones y están compuestos por asociaciones de igual naturaleza que en el caso anterior.

${ }^{26}$ Posibilidad que puede quedar reflejada en los Reglamentos Orgánicos de Participación, de existencia obligatoria en todos los municipios según el art. 70 bis 1 de la LrBRL, a través de figuras como los foros de debate, encuestas y sondeos de opinión, reuniones informativas, etc.
} 
mental, en la medida en que antes de adoptarse el acuerdo formal de inicio de la elaboración del Plan cabe la posibilidad de elaborar Avances y Anteproyectos, la apertura de periodos de información y exposición pública de trabajos preliminares para formular sugerencias y alternativas, etc.

En el presente epígrafe vamos a referirnos, de manera sucinta, al tratamiento que la jurisprudencia ha dado a la pretendida conexión del derecho a participar en el procedimiento de formación de Planes urbanísticos con el derecho a participar directamente en los asuntos públicos establecido en el art. 23.1 CE que, en ocasiones, ha sido invocada por las partes en los correspondientes procesos jurisdiccionales, en dos manifestaciones concretas como son el trámite de información pública y la consulta popular municipal.

\section{1. La exclusión del contenido del art. 23.1 CE de la información pública en el procedimiento de elaboración del planeamiento}

Una primera aproximación a la cuestión apuntada, induce a plantear la posible existencia de una interconexión entre la consagración de la cláusula de Estado Democrático y Social -art. 1.1 CE-, la obligación que compete a los poderes públicos para facilitar la participación de todos los ciudadanos en la vida política, económica, cultural y social -art. 9.2 CEy el derecho de aquéllos a participar directamente en los asuntos públicos -art. 23.1 CE -27 . Pero tal posibilidad se ve cercenada por una conocida jurisprudencia restrictiva del $\mathrm{TC}^{28}$, que ha interpretado que la «participa-

\footnotetext{
${ }^{27}$ Máxime si se tiene en cuenta que, a los efectos de su delimitación subjetiva, el TC ha interpretado desde fecha temprana que el art. $23 \mathrm{CE}$ tiene como destinatarios a los ciudadanos y no a otros entes o sujetos de la comunidad, STC 23/1983, de 25 de marzo, F.J. $4^{\circ}$.

${ }^{28}$ No han faltado las críticas a esta consolidada jurisprudencia constitucional formuladas desde diferentes planteamientos. Con carácter general pueden verse las objeciones que formulan A. Sánchez Blanco: «Los derechos de participación, representación y de acceso a funciones y cargos públicos; la corrección de la unilateral perspectiva política», en VVAA, La Participación, Anuari de la Facultad de Dret, Estudi General de Lleida, Barcelona, 1985, pp. 227-254; L. Aguiar de Luque y Ma. D. GonZÁlez Ayala: «Artículo 23.1. El Derecho a participar en los asuntos públicos», en O. Alzaga (dir.), Comentarios a la Constitución Española de 1978, Tomo II, Edersa/Cortes Generales, Madrid, 1997, pp. 651-654; en la materia que nos ocupa, véanse J. GonZÁLEZ PÉREZ: «Artículo 6», en: Comentarios a la Ley sobre Régimen del Suelo y Valoraciones. (Ley 6/1998, de 13 de abril), Civitas, Madrid, 1998, p. 116, y F.J. ENÉRIz OlAECHEA, op.cit, p. 195, autores que al tratar el tema de la participación ciudadana en el procedimiento de elaboración de planes urbanísticos enumeran entre los preceptos constitucionales que la fundamentan, además de los arts. 9.2 y 105.a), el reiterado art. 23.1 CE.
} 
ción» a la que hace mérito el precitado art. 23.1 CE se reduce de modo exclusivo a la «participación política», excluyendo la participación administrativa.

Con carácter preliminar, resulta oportuno apuntar dos cuestiones iniciales que se plantean a la hora de analizar el citado precepto constitucional ${ }^{29}$. De una parte, hay que tener presente que los dos apartados del art. $23 \mathrm{CE}$ se encuentran conceptualmente en una síntesis difícilmente indisociable; y, de otra, al igual que sucede con las nociones de «funciones» y «cargos públicos» que aparecen en el apartado segundo, el concepto de «participación directa» al que se refiere el primer apartado goza de cierta imprecisión terminológica, que ha sido delimitado a través de una función constructiva de la jurisprudencia constitucional en orden a perfilar el contenido esencial del derecho fundamental a la participación directa en los asuntos públicos.

En efecto, nuestro Tribunal Constitucional partiendo del criterio de que no se trata de un derecho a que los ciudadanos participen en los asuntos públicos cualquiera que sea su clase, ha delimitado el contenido material de este derecho mediante la figura del denominado «especial llamamiento» o «especial competencia», si se trata de órganos públicos, o de la «especial legitimación» en el caso de entidades o sujetos de derecho privado $^{30}$. Noción que el propio TC ha perfilado restrictivamente al afirmar que «debe ser además un llamamiento a intervenir directamente en la toma de decisiones políticas para que pueda considerarse como una facultad incluida en el ámbito constitucionalmente protegido del derecho de participación ex artículo 23.1 CE» ${ }^{31}$.

Esta construcción jurisprudencial posee, además, la virtualidad de delimitar en sus vertientes positiva y negativa el contenido del art. 23.1 CE. En su aspecto positivo, la participación ciudadana directa en los asuntos públicos se limita por el TC a las elecciones de los miembros de las Cortes Generales y, por extensión, de las Asambleas Legislativas Autonómicas y Corporaciones Locales -STC 51/1984, de 25 de abril, F.J. $2^{\circ}-$; a las consultas populares previstas en la Constitución ${ }^{32}$-STC 63/1987, de 20

\footnotetext{
29 Al respecto, vid., J. GARcía RocA: Cargos públicos representativos. Un estudio del artículo 23.2 de la Constitución, Aranzadi, Pamplona, 1999, p. 29 y ss.

30 Salvo error por nuestra parte, es en la STC 51/1984, de 25 de abril, donde aparece por vez primera el criterio del «especial llamamiento», (F.J. $2^{\circ}$ ), en los términos expuestos.

31 SSTC 119/1995, de 17 de julio, F.J. 5º y 167/2001, de 16 de julio, F.J. 5º, entre otras.

32 Arts. 92, 149.1.32 a $150.1,152.2,167.3$ y 168.3 CE.
} 
de mayo, F.J. $5^{\circ}-$; la iniciativa legislativa popular del art. 87.3 CE -STC 76/1994, de 14 de marzo, FF.JJ $3^{\circ}$ y $4^{\circ}-$; y, por último, al régimen del Concejo Abierto -STC 119/1995, de 17 de julio F.J.3º. Como se observa, todos los supuestos que el TC ha considerado que forman parte del contenido de la participación directa en los asuntos públicos son aquellos en los que, en principio, concurren dos notas distintivas. En primer lugar, se trata de actos dotados de un alto contenido político y, en segundo término, la participación se ejercita a través de un llamamiento específico al sujeto titular de la soberanía, esto es, el pueblo considerado en su globalidad o conjunto. Quedarían fuera del art. 23.1 CE, en definitiva, otros ámbitos como los títulos participativos que se derivan bien de otros derechos fundamentales, bien de normas constitucionales de distinta naturaleza, bien de su reconocimiento legislativo. Es decir, su contenido no sería tanto un genérico derecho a participar en los asuntos públicos, como el ejercicio del poder político bien directamente por los propios ciudadanos, bien indirectamente a través de representantes ${ }^{33}$.

La trascendencia de la hermenéutica constitucional apuntada, se traduce en la exclusión de la cobertura de la protección y tutela que proporciona el derecho fundamental, respecto de otras modalidades participativas derivadas de títulos contenidos en otras normas constitucionales, específicamente el mandato a los poderes públicos previsto en el art. 9.2 CE. En efecto, dicho precepto no se configura como un derecho fundamental, pues de otro modo el art. 23.1 CE no sería nada más que una mera cláusula reiterativa e inútil, sino como un mandato constitucional dirigido a facilitar «la participación de todos los ciudadanos en la vida política, económica, cultural y social». Mandato que se traduce, más bien, en un objetivo o propósito finalista al que debe tender la acción de los poderes públicos y, así mismo, como medio necesario para alcanzar los valores superiores de libertad e igualdad proclamados en su primer inciso $^{34}$.

\footnotetext{
${ }^{33}$ En palabras de la STC 119/1995, de 17 de julio, para determinar si se está en presencia o no de un derecho de participación política, encuadrable en el art. 23.1 CE, habrá que atender «no sólo a la naturaleza y forma del llamamiento, sino también a su finalidad: sólo allí donde la llamada a la participación comporte, finalmente, el ejercicio, directo o por medio de representantes, del poder político -esto es, sólo allí donde se llame al pueblo como titular de ese poder- estaremos en el marco del art. 23.1 CE». (F.J.5 $5^{\circ}$. Queda, pues, trazada perfectamente por el TC la relación entre la atribución de la titularidad de la soberanía nacional al pueblo español contenida en el art. $1.2 \mathrm{CE}$ y la participación ciudadana directa en los asuntos públicos prevista en el reiterado art. $23.1 \mathrm{CE}$.

${ }^{34}$ Sobre estas cuestiones son muy útiles las reflexiones que hace más de veinticinco años efectuaba M. SÁNCHEZ MORÓN: «El principio de participación en la Constitución española», RAP, n. ${ }^{\circ} 89$, 1979, p. 175 y ss.
} 
En sentido negativo, y en coherencia con la hermenéutica constitucional en virtud de la cual se vincula el derecho a participar en los asuntos públicos con la adopción de decisiones de naturaleza política derivadas de una manifestación de la soberanía popular, el TC ha descartado sucesivamente que en el precepto comentado se puedan encuadrar, entre otras modalidades participativas, las elecciones a un Colegio Profesional -STC 23/1984, de 20 de febrero-, la participación de un Sindicato en la elaboración de un Convenio -STC 51/1984, de 25 de abril-, la elección de representantes sindicales -STC 189/1993, de 14 de junio-, la participación en los órganos rectores de una Facultad -STC 212/1993, de 28 de junioy, por último, la falta de convocatoria para asistir a las sesiones de una Fundación Municipal -STC 167/2001, de 16 de julio-.

Centrándonos en la materia que nos ocupa, hay que señalar que tanto el TC como el TS han tenido ocasión de conocer litigios en que los recurrentes invocaban una presunta violación del derecho a participar directamente en los asuntos públicos, vinculada al trámite de información pública en la elaboración de los Planes urbanísticos. En este sentido, la STC 119/1995, de 17 de julio, tiene por objeto determinar si la omisión por parte del Ayuntamiento de Barcelona de la apertura de un segundo trámite de información pública antes de la aprobación provisional de un Plan Especial, en el que se habían introducido modificaciones sustanciales, puede implicar no sólo una infracción de legalidad ordinaria sino también una vulneración del referido derecho fundamental.

El Alto Tribunal, asumiendo una consolidada jurisprudencia del TS en orden a la concreción constitucional ex art. 105.a) del requisito de la información pública en la elaboración de los instrumentos urbanísticos, rechaza que el derecho pretendidamente vulnerado sea un derecho de participación política incardinable en el art. 23.1 CE. La doctrina constitucional puede concretarse, sumariamente, en dos aspectos. En primer término, la participación ciudadana en la elaboración del Planeamiento, instrumentalizada formalmente a través del trámite de información pública, es una participación en la actuación administrativa «que no es tanto una manifestación del ejercicio de la soberanía popular cuanto uno de los cauces de los que en un Estado social deben disponer los ciudadanos para que su voz pueda ser oída en la adopción de las decisiones que les afectan». (F.J.6 ${ }^{\circ}$ ). De manera que no supone una participación política en sentido estricto, sino una participación en la actuación administrativa de carácter funcional o procedimental, que garantiza tanto la corrección del procedimiento cuanto los derechos e intereses legítimos de los ciudadanos. 
En segundo lugar, entiende el TC que si bien el trámite de información pública opera como un factor coadyuvante de cierta legitimación popular del Plan -legitimidad democrática que, en todo caso, dimana directamente del hecho de que ha sido aprobado por un Ayuntamiento elegido democráticamente-, su finalidad no es realizar un llamamiento al electorado para que ratifique una decisión previamente adoptada, sino más bien, instar a quienes tengan interés o lo deseen a expresar sus opiniones para que sirvan de fuente de información de la Administración y puedan favorecer el acierto y oportunidad de la medida que se vaya a adoptar, así como establecer un cauce para la defensa de los intereses individuales o colectivos de los potencialmente afectados.

El TS, en similares términos a los acabados de exponer, ha rechazado de plano cualquier alegación de vulneración del art. 23.1 CE en el procedimiento de elaboración de instrumentos urbanísticos. En este sentido se manifiestan las SSTS de 7 de diciembre de 2001 y 6 de mayo de $2002^{35}$. En los dos casos se había alegado la violación del art. 23.1 CE, en relación con los arts. 41 TRLS/76 y 127 a 130 y 132 RPU, para demostrar que no se había verificado en la forma legalmente prevista el trámite de información pública en la tramitación de la elaboración de dos Planes Parciales. Ante la pretendida vulneración denunciada, el TS, tras recordar que el reiterado art. 23.1 CE contempla el derecho fundamental a la participación ciudadana a través de mecanismos de democracia directa, semidirecta y representativa, desestima en términos lacónicos cualquier violación del precepto constitucional en la medida en que el mismo «no reza para el trámite de información pública en la elaboración de un Plan Parcial».

Como se infiere de las tres Sentencias mencionadas, coherentes con una consolidada jurisprudencia constitucional, el trámite de información pública en el procedimiento de elaboración de instrumentos de planeamiento no forma parte del contenido esencial del derecho a participar directamente en los asuntos públicos proclamado en el art. 23.1 CE por dos motivos. El primero, por cuanto no se trata de una manifestación de la participación política de la comunidad en el ejercicio de la soberanía popular, sino de la participación ciudadana en la actuación administrativa al objeto de garantizar la legalidad del procedimiento. Y, el segundo, en estrecha relación con lo acabado de exponer, porque su objeto no consiste en que el cuerpo electoral ratifique una decisión previamente acordada,

35 SSTS de 7 de diciembre de 2001, Ar. 4913, F.D. $12^{\circ}$ (J. RoDRíGUEZ-ZAPATA); y de 6 de mayo de 2002, Ar. 9552 , F.D. $12^{\circ}$ (P.J. YAGÜE GIL). En ambos supuestos se recurre por la misma parte actora, una empresa constructora, sendas Sentencias del Tribunal Superior de Justicia de Aragón desestimatorias recaídas sobre los acuerdos municipales de aprobación definitiva de Planes Parciales de la ciudad de Zaragoza. 
como ocurriría por ejemplo con la consulta popular. Por el contrario, su función estriba en servir de cauce para que las opiniones de los ciudadanos provean de la información necesaria al órgano municipal encargado de aprobar la concreta ordenación urbanística de que se trate y, en consecuencia, que éste adopte la solución más acorde con los intereses de la comunidad dotándola, por lo tanto, de la necesaria legitimación social.

La conclusión que se deduce de esta jurisprudencia constitucional implica que la participación administrativa no forma parte del contenido del art. 23.1 CE, de modo que en aquellos supuestos en que el ejercicio por los ciudadanos del trámite de información pública en el procedimiento de elaboración de planes urbanísticos pueda verse afectado o vulnerado, carecen de la protección jurisdiccional privilegiada que confiere el recurso de amparo constitucional ${ }^{36}$.

Toda vez que hemos visto sumariamente cómo el TC y el TS rechazan $a$ radice que el trámite de información pública en el procedimiento de elaboración del Planeamiento Urbanístico pueda configurarse como una modalidad participativa subsumible en el reiterado art. 23.1 CE, corresponde a continuación examinar el tratamiento que la jurisprudencia ha conferido a la segunda manifestación de intervención ciudadana en dicho procedimiento vinculada con tal precepto constitucional, esto es la consulta popular municipal.

\section{2. La consulta popular municipal como acto previo a la elaboración material del plan y su posición privilegiada respecto de otras modalidades participativas}

A pesar de que, tal y como hemos reiterado en páginas precedentes, la legislación urbanística ha materializado la participación ciudadana en el proceso de elaboración de los planes prácticamente en exclusiva mediante el trámite de la información pública en sus diferentes fases, el ordenamiento jurídico positivo nos ofrece otra posibilidad de intervención de la comunidad local en dicho procedimiento a través de la consulta popular munici-

\footnotetext{
36 J.A. Santamaría Pastor: «Artículo 23», en F. Garrido Falla (dir.), Comentarios a la Constitución, $3^{\text {a }}$ ed., Civitas, Madrid, 2001, en especial, pp. 513-518. No han faltado las propuestas dogmáticas de extender la cobertura del art. 23.1 CE a todos los mecanismos y modalidades de participación directa de los ciudadanos en los procedimientos de decisión de los poderes públicos que establece la Constitución, específicamente en lo que aquí interesa, en el supuesto del derecho de aquéllos a intervenir en el procedimiento de elaboración de las disposiciones administrativas que les afecten reconocido en el art. 105.a) CE; vid. L. Aguiar de LuQue y Mª.D. GonzÁlez Ayala, op. cit., p. 659; y A. PÉreZ MORENo, op. cit., pp. 125 y ss.
} 
pal. No obstante la existencia de tal previsión legislativa contemplada expresamente en la LrBRL, su empleo como elemento coadyuvante de la toma de decisiones y adopción de acuerdos por las Corporaciones Locales dista mucho de ser una realidad habitual y constante, incluido su uso en la confección de instrumentos de planeamiento urbanístico ${ }^{37}$. En este sentido, parece oportuno recordar que desde la entrada en vigor de la LrBRL en 1985 hasta 2004, de los noventa y cuatro expedientes de consulta popular municipal tramitados por el Ministerio de Administraciones Públicas sólo se autorizaron veinte, archivándose o denegándose, según los casos, los restantes. Del número total de consultas sólo cinco guardaban relación directa con la materia que nos ocupa y, de ellos, exclusivamente se autorizó uno ${ }^{38}$.

Tanto el TS como el TC han tenido ocasión de conocer recursos que versaban sobre dicho instituto. En efecto, las SSTS de 9 de mayo de 1997 y 14 de noviembre de $1997^{39}$ desestiman sendos recursos de casación en los que se impugnan la Orden de Medidas Complementarias aprobada por el Ayuntamiento de Palamós para la celebración de la consulta popular, en el primer caso, y el correspondiente Decreto de la Generalidad de Cataluña de convocatoria de dicha consulta sobre la calificación urbanística de los ámbitos denominados «Paratge de Castell y Plana de Castell» en el segundo ${ }^{40}$. En ambos supuestos las pretensiones de los actores se fundan en la violación del art. 23.1 CE sobre la base de la inexistencia de legislación aplicable a dicho instrumento de participación. Por su parte, el ATC 25/1998, de 26 de enero, inadmite el recurso de amparo interpuesto contra la precitada Sentencia de 9 de mayo de 1997, que el recurrente basaba en iguales argumentos que los empleados ya ante el Tribunal a quo.

A los efectos que ahora interesan, de la doctrina que contienen las Sentencias reseñadas, importa destacar los aspectos sustanciales sobre los que

\footnotetext{
37 Como se observa, estamos en presencia de una técnica participativa de escasa utilización, que pone de relieve la tensa dialéctica entre las instituciones de democracia representativa y de democracia directa. Sobre los «efectos perversos» de la generalización de la consulta popular municipal resulta ilustrativo: L. GARCÍA HERNÁNDEZ y E. SANJUÁN DE LA FUENTE: «Consultas populares y participación ciudadana», en T. FonT (dir.), Informe sobre el Gobierno Local, MAP/Fundació Carles Pi i Sunyer, Madrid, 1992, en especial pp. 414-418.

38 Las materias sobre las que versaban tales consultas eran la calificación urbanística de dos parajes - la única autorizada-; la urbanización de un pinar; la inclusión de una finca como suelo urbanizable; la ampliación del casco urbano; y, por último, la utilización de determinados instrumentos de planeamiento.

39 SSTS de 9 de mayo de 1997, Ar. 4527 y de 14 de noviembre de 1997, Ar. 8661; en ambas, el ponente fue E. CANCER LALANNE.

40 Resulta de interés la lectura de la tramitación administrativa de esta consulta popular en: J.M. TrAYTER JimÉnEZ, El control del planeamiento urbanístico, op. cit., pp. 214-220.
} 
se construye la argumentación del TS y del TC en orden a rechazar el fundamento de la alegada infracción del art. 23.1 CE. En primer lugar, y en contra de la pretensión del recurrente, el TS afirma rotundamente la existencia de normativa ordinaria suficiente para fundamentar la validez constitucional de la Orden Municipal y el Decreto impugnados, integrada por una pléyade de normas estatales y autonómicas ${ }^{41}$ que dan por satisfecho el carácter de derecho de configuración legal que se predica del art. 23.1 CE.

En segundo término, el TC entiende que el recurrente no persigue impugnar una decisión prohibitiva o restrictiva del derecho de participación política, sino una decisión «que permite el ejercicio por los ciudadanos del derecho a emitir su opinión sobre la calificación de unos terrenos»». En definitiva, lo que pretende el actor, afirma el TC, «no es una decisión de protección del derecho fundamental, sino el control por el Tribunal Constitucional de un eventual exceso en la configuración de un derecho de participación ciudadana en asuntos de interés general» (F.J. $3^{\circ}$ ).

Como se observa, el TC despeja con claridad que las pretensiones de los recurrentes no se fundan en una violación del derecho a participar directamente en los asuntos municipales, sino, por el contrario, en un exceso del desarrollo normativo de un derecho de configuración legal como es el art. 23.1 CE.

Por ello, se ha afirmado que las sentencias comentadas producirían el efecto de legitimar la consulta popular en el ámbito del urbanismo ${ }^{42}$. A nuestro modo de ver, la conclusión que se deduce de las mismas debe ir más allá, en el sentido de entender que estamos en presencia de la manifestación de una modalidad de participación política de la comunidad vecinal, en los términos delimitados por la jurisprudencia del TC señalada al inicio de este epígrafe, dirigida a la elección de un modelo de ordenación urbana concreta. No se trataría, pues, de la mera garantía de participar en el procedimiento administrativo de elaboración de una disposición de carácter general amparada por el art. 105.a) CE, una técnica de participación administrativa, sino de una manifestación del contenido positivo del art. 23.1 CE, amparado por las garantías y recursos que la CE previene para esta clase de derechos fundamentales en los supuestos de su posible violación.

\footnotetext{
41 Entre las que el TS cita las siguientes: los arts. 144 a 146 de la Ley 8/1987, de 15 de abril, Municipal y de Régimen Local de Cataluña; Ley Orgánica 2/1980, de 18 de enero, reguladora de las distintas modalidades de referéndum; Ley Orgánica 5/1985, de 19 de junio, de Régimen Electoral General; y, por último, el art. 71 de la Ley 7/1985, de 2 de abril, reguladora de las Bases de Régimen Local.

42 En este sentido se manifiesta E. SÁNCHEZ GoYANES: La potestad normativa del municipio español, El Consultor, Madrid, 2000, p. 452, al reseñar las dos sentencias del TS citadas.
} 
La razón estriba en que en el supuesto concreto de la consulta popular municipal concurren los dos presupuestos fácticos requeridos por el TC para entender que la misma es una modalidad del referido derecho fundamental: en primer lugar, en la medida en que se trata de una manifestación de la participación política de la comunidad local en el ejercicio de la soberanía popular y, en segundo término, porque la finalidad del llamamiento que se efectúa a dicha comunidad local consiste en ratificar una decisión previamente acordada por un órgano de naturaleza democráticorepresentativa como es el Pleno municipal.

En definitiva, de la interpretación jurisprudencial acabada de exponer y de las recientes modificaciones legislativas operadas en la LrBRL relativas a la regulación de las consultas populares ${ }^{43}$, podemos entender que el mencionado instituto, como mecanismo de participación ciudadana directa en la formación de planes urbanísticos, proporciona grandes expectativas en cuanto a su utilización, sin olvidar en cualquier caso las complejidades procedimentales que requiere su celebración y los problemas que genera ${ }^{44}$.

\section{LA PARTICIPACIÓN CIUDADANA PREVIA AL ACUERDO MUNICIPAL DE APROBACIÓN INICIAL DE LOS INSTRUMENTOS DE PLANEAMIENTO. LOS AVANCES Y TRABAJOS PRELIMINARES}

En la formación de los instrumentos de planeamiento urbanístico, como es notorio, confluyen la elaboración y confección previa de traba-

\footnotetext{
${ }^{43}$ Modificaciones que traen causa de la Recomendación Rec. (2001) 19, del Comité de Ministros a los Estados miembros sobre la participación de los ciudadanos en la vida pública en el nivel local. Esta Recomendación configura una serie de principios generales como elementos esenciales de una «política de la participación democrática en el nivel local», que constituyen «el núcleo duro de la Recomendación», según su propia terminología, entre los que aparece el de "considerar la cuestión de la participación de los ciudadanos en su conjunto, teniendo en cuenta a la vez mecanismos de democracia representativa y formas de participación directa en el proceso decisional y en la gestión de los asuntos locales».

${ }^{44}$ Sobre el complejo trámite para la convocatoria y celebración de consultas populares municipales que, en no pocas ocasiones, opera como un factor de desistimiento de los Ayuntamientos interesados haciéndoles huir hacia fórmulas alegales de consulta, vid., J.M. TRAYTER JIMÉNEZ, op. cit., pp. 194-214; y J. BARATA I MiR: Los actos de gobierno en el ámbito municipal, Tecnos, Madrid, 1999, pp. 178-216. Por su parte, resulta útil para conocer una exposición de los problemas e incertidumbres que provoca la extensión generalizada de la consulta popular en un supuesto concreto, C. Needham: «Consulation: A Cure for Local Government?», Parliamentary Affairs, n. ${ }^{\circ}$ 5, vol. 55, 2002, pp. 699-714, relativo a la generalización de las consultas y la participación que se había marcado como objetivo el Gobierno de T. BLAIR en el libro blanco de 1998 Modern Local Government: In Touch with the People.
} 
jos, análisis y estudios técnicos de excesiva complejidad, que resultan en no pocas ocasiones de difícil, cuando no imposible, comprensión para gran parte de la sociedad. Por ello, si se llega al extremo de sobredimensionar la actividad de los equipos redactores, integrados por profesionales procedentes de diferentes disciplinas -arquitectos, geógrafos, juristas, sociólogos, economistas, etc.-, se puede generar el riesgo de tecnificar en exceso la actividad de ordenación urbanística configurándola exclusivamente como una «función puramente técnico-administrativa» ${ }^{45}$. Por esta razón, el procedimiento de elaboración de los planes, y con la finalidad de evitar esa posible disfunción, debe ir acompañado de los adecuados mecanismos correctores de información, asesoramiento y participación de los ciudadanos afectados por la concreta ordenación urbanística de que se trate.

Esta labor debe satisfacerse, entre otras actuaciones, mediante el fomento de la participación pública en la formulación y ejecución del planeamiento a través de mecanismos específicos como son: la difusión de las propuestas de ordenación mediante un lenguaje claro, la utilización de foros adecuados en función de las áreas afectadas -Juntas de Distrito, Asociaciones de Vecinos, etc.-, y medios de comunicación adecuados para que los vecinos puedan formarse una opinión ${ }^{46}$. En este sentido, hay que recordar que la jurisprudencia ha puesto de relieve la trascendencia que para la sociedad posee el planeamiento al concebirlo como «una decisión capital» que va a condicionar el desarrollo de la vida de los ciudadanos al ir dirigido a «trazar el entorno determinante de un cierto nivel de calidad de vida $\rangle^{47}$, que precisa de la necesaria participación de los afectados por el mismo en su procedimiento de elaboración, con el objeto de

\footnotetext{
${ }^{45}$ Cfr., L. Parejo Alfonso, Derecho urbanistico. Instituciones básicas, op. cit., p. 358.

46 Vid., al respecto las «Recomendaciones finales de avance normativo y política de suelo» del Informe sobre Suelo y Urbanismo de la Comisión de Expertos sobre Urbanismo, en: Ciudad y Territorio. Estudios Territoriales, n. ${ }^{\circ}$ 103, 1995, p. 185.
}

47 Cfr., entre otras, las SSTS de 18 de septiembre de 1987, Ar. 8303, F.D. $3^{\circ}$ (Modificaciones introducidas tras la aprobación definitiva del Proyecto de Delimitación del Suelo Urbano de Cascante); 30 de enero de 1989, Ar. 579, F.D. $2^{\circ}$ (Revisión y adaptación del PGOU de La Garriga); 30 de octubre de 1990, Ar. 8428, F.D. $2^{\circ}$ (Modificaciones introducidas en la aprobación definitiva de Plan Parcial de Conil de la Frontera); y de 9 de julio de 1991, Ar. 5737, F.D. $2^{\circ}$ (PGOU de Castillo-Playa de Aro), de todas ellas ponente F.J. Delgado BARRIo. Concepción funcional del planeamiento que, por otra parte, resulta tributaria de diferentes principios y postulados constitucionales: $a$ ) de la obligación que compete a los poderes públicos de velar por la utilización racional de los recursos naturales al objeto de garantizar un cierto nivel de calidad de vida contenida en el art. 45.2 CE; $b$ ) del derecho a disfrutar de una vivienda digna y adecuada y del correlativo deber legislativo de los poderes públicos encaminado a establecer una ordenación del suelo que haga efectivo ese derecho concretado en el art. $47 \mathrm{CE}$; y, c) del principio de eficacia que debe presidir toda actuación de la Administración Pública consagrado en el art. 103 CE. 
que sus determinaciones se adecuen lo más posible a la realidad de las exigencias, aspiraciones y necesidades de la comunidad local, esto es, que sea un plan eficaz en cuanto a sus fines ${ }^{48}$.

No hay que obviar, por lo expuesto, que el plan se traza pensando en primer término en la ciudad y en sus habitantes y no en los propietarios de los terrenos, pues la utilización del suelo, tal y como reitera el TS, ha de regularse de acuerdo con el interés general constitucionalizado en el art. $47 \mathrm{CE}^{49}$. De modo que la intervención ciudadana debe ejercerse ya en la fase preliminar en la que se articulan las primeras actuaciones técnicas para la formación del plan, y no diferirse exclusivamente al procedimiento administrativo formal de tramitación del mismo.

La jurisprudencia del TS y de los TSJ de las Comunidades Autónomas se ha ocupado preferentemente de perfilar los contornos básicos de la participación ciudadana en dos aspectos fundamentales de la fase inmediatamente anterior a la adopción del acuerdo municipal de aprobación inicial de los instrumentos de ordenación urbanística. En primer lugar, en cuanto a la potestad de la Administración competente para abrir un periodo de información pública previo a la elaboración de cualquier Plan de ordenación, Norma o Programa, con la finalidad de recoger sugerencias u observaciones sobre la necesidad, conveniencia y demás circunstancias de la ordenación. Y, en segundo término, respecto del deber de exposición pública de los trabajos preparatorios de elaboración de los Planes Generales, cuando hayan adquirido el suficiente grado de desarrollo que permita formular los criterios, objetivos y soluciones generales del planeamiento, al objeto de facilitar la formulación de sugerencias y alternativas del planeamiento.

\section{1. El Avance de planeamiento y el carácter potestativo de la información pública anterior a la aprobación inicial del plan}

Como elementos que coadyuven a que la elección municipal del modelo de ordenación urbanística sea lo más acorde con la realidad físi-

\footnotetext{
48 Tal y como señala la STS de 24 de septiembre de 1999, Ar. 7953, F.D. $6^{\circ}$ (J. RodríGuEZ-ZAPATA, modificación del PGOU de Soria), «las exigencias de publicidad y de participación pública son esenciales en la elaboración del planeamiento, ya que el mismo nace con vocación de ser cumplido, por lo que debe acomodarse al máximo a la realidad, para asegurar que el suelo y los servicios previstos para el futuro existirán y, a ser posible se encontrarán en los sitios adecuados para ello».

49 STS de 10 de junio de 1992, Ar.5074, F.D. $7^{\circ}$ (J. Barrio Iglesias, Plan Parcial de Bañolas).
} 
ca, social, económica y jurídica del ámbito que pretende regular, la legislación urbanística, estatal a partir de 1978 y autonómica en la actualidad, contempla dos mecanismos participativos preliminares a la adopción del acuerdo de aprobación inicial de los planes. Concretamente nos estamos refiriendo a la posibilidad de que por la Administración, de una parte, se formulen Avances de planeamiento en los que el Ayuntamiento puede manifestar ya sus preferencias por una determinada opción planificado$\mathrm{ra}, \mathrm{y}$, de otra parte, a la facultad de acordar la apertura de un periodo de información pública al objeto de recoger sugerencias u observaciones sobre la necesidad, conveniencia y demás circunstancias de la ordenación $^{50}$.

Por lo que respecta a los Avances, debemos resaltar que, según una consolidada línea jurisprudencial, la participación comunitaria en esta fase preliminar de elaboración del planeamiento se ve limitada por la propia naturaleza jurídica de aquéllos. Valga reseñar a estos efectos que es prácticamente unánime la doctrina que declara la limitada finalidad de tales instrumentos «al servir de orientación a la redacción de los planes y, por ende, su mera eficacia administrativa interna, preparatoria sin alcance vinculante de la formación» de los mismos ${ }^{51}$. De manera que la exclusiva finalidad de servir de orientación a la redacción del Plan implica que «el contenido del Avance [no] tenga que condicionar definitivamente el sentido de las determinaciones futuras del Plan $\rangle^{52}$.

La consecuencia que se infiere de la naturaleza no vinculante y de mera eficacia interna del Avance estriba en que el acuerdo municipal de aprobación del mismo, cuando se ha obviado el trámite de información pública, no puede ser objeto de impugnación autónoma al tratarse de un acto de trámite, es decir, «es clara la inimpugnabilidad de lo que no es más que un acto preparatorio -arts. 37 y 82.c) LJ 1956 y 25 y 69 LJ 1998- [...] siendo efectivamente los acuerdos de aprobación definitiva que en su día

\footnotetext{
${ }^{50}$ Como es notorio, ambos mecanismos participativos tienen su origen en los arts. 115 y 116 del RPU que, con mayor o menor literalidad, han sido recogidos en la legislación urbanística autonómica al regular el procedimiento de elaboración y aprobación del planeamiento.

${ }^{51}$ STS de 17 de marzo de 1986, Ar. 1831, (V. MARín RuIZ, Redacción del Avance de Plan Especial de Reforma Interior en el Viejo Cauce del Río Turia de Valencia) en esta ocasión el TS resuelve un recurso interpuesto por el Colegio Oficial de Arquitectos de Valencia contra el acuerdo municipal de contratación de la redacción de un Plan Especial de Reforma Interior.

52 STS de 13 de julio de 1988, Ar. 6076, F.D. $6^{\circ}$ (J. García-Ramos IturRalde, Normas Subsidiarias de Santanyí). Por su parte, la STS de 15 de abril de 1988, Ar. 3074, (P. MARTín MARTín, Normas Subsidiarias de Cañar) deduce la innecesariedad de publicar los Avances por el hecho de tener efectos puramente administrativos, internos y preparatorios de la redacción de planes y proyectos. (F.D. $5^{\circ}$ de la sentencia apelada y asumida por el TS).
} 
se dicten -inicial y provisional- los susceptibles de ser sometidos a la impugnación en vía jurisdiccional» ${ }^{53}$.

Los limitados efectos de la participación ciudadana en la fase preliminar del procedimiento de confección de los planes se deja sentir, asimismo, en cuanto a las funciones y efectos del trámite de información pública cuya apertura puede acordar el Ayuntamiento. En efecto, la jurisprudencia, en una interpretación literal de la legislación urbanística, ha incido en dos aspectos de primer orden en esta materia. De una parte, ha rechazado, en función de su naturaleza potestativa y no preceptiva, que la omisión del referido trámite pueda constituir infracción alguna del ordenamiento jurídico ${ }^{54}$. Y, de otra parte, ha delimitado el carácter no vinculante de las propuestas, sugerencias y alternativas de quienes intervienen en la exposición pública delimitando un doble efecto: primero, resulta improcedente sostener una pretensión de nulidad por no ser atendidas o incorporadas al Plan de que se trate; y, segundo, la aportación de sugerencias al Avance por los interesados no implica su incorporación definitiva al concreto instrumento urbanístico, sino que éste se nutre a través de las diversas aportaciones efectuadas en las aprobaciones inicial, provisional y definitiva ${ }^{55}$.

Pero incluso en el supuesto de formulación de alegaciones por los ciudadanos en las fases procedimentales acabadas de señalar, la Administración no tiene obligación alguna de acogerlas, pues la decisión final sobre el contenido del planeamiento es competencia exclusiva de los órganos administrativos. De suerte que aquélla sólo tiene obligación de «abrir el trámite de información pública que permita formularlas [las alegaciones]» ${ }^{56}$, pero no

${ }^{53}$ STSJ de Galicia n. ${ }^{\circ}$ 915/2001, de 24 de mayo, Ar. 2001/815 (J.M a ARrojo MARTínEZ, aprobación del Avance de un Estudio de Detalle de la ciudad de Lugo).

${ }^{54}$ STS de 23 de octubre de 1989 (precitada), F.D.5 $5^{\circ}$ de la sentencia apelada y asumido por el TS.

55 STS de 23 de octubre de 1989 y STSJ de Andalucía, n. ${ }^{\circ}$ 149/2001, de 5 de marzo, Ar. 2001/1129, (J.A. Santandreu Montero, Revisión de las Normas Subsidiarias de Alfacar). Esta última Sentencia delimita la finalidad de la información pública por el hecho de «obtener una base lo más aproximada de orientación y de mayoritaria aceptación en principio. Su contenido no alcanza, no se identifica con el de las Normas Subsidiarias a que se refiere, limitándose a las líneas maestras -bases- o esquema a los que deben responder, en principio, las determinaciones sustanciales de las Normas a desarrollar. La aceptación por los órganos o entidades intervinientes de las bases tiene una eficacia orientativa y sólo de principio. Ni siquiera para sus autores son vinculantes».

${ }^{56}$ STS de 10 de diciembre de 1996, Ar. 9206, F. D. $2^{\circ}$ (J.M. SANZ BAYÓN, Normas Subsidiarias de Archena). Y ello a pesar que el propio Tribunal afirma que la finalidad de la información pública consiste en que «la decisión de la Administración urbanística actuante se vea precedida de un previo debate social, en aras de que las sugerencias y observaciones así formuladas contribuyan a la mejor formación de la voluntad que ha de plasmarse en los sucesivos actos administrativos que jalonan la tramitación del procedimiento, y de que esta voluntad coincida con las exigencias sociales». 
de asumirlas. Sin perjuicio, claro está, de la obligación municipal de estudiar y evaluar las posibles sugerencias recibidas y tratar de integrarlas en el plan de que se trate.

\section{2. La intervención ciudadana en el trámite de exposición al público de los trabajos preparatorios del Plan}

De la lectura de la jurisprudencia recaída sobre esta materia, la primera cuestión que llama la atención es el carácter instrumental que tiene para la Administración urbanística la participación de la comunidad en la exposición pública de los trabajos previos del plan. De modo que, en función del resultado de la exposición a que se refiere el art. 125.1 RPU, las alegaciones formuladas y de los estudios técnicos realizados, «la Administración acordará lo procedente en cuanto a los criterios y soluciones con arreglo a los cuales hayan de culminarse los trabajos de elaboración del Plan ${ }^{57}$. Interpretación que resulta coherente con la concepción de la participación que maneja nuestro TS, al entender que ésta tiene por objeto proporcionar elementos de juicio a la Administración correspondiendo la decisión última sobre el concreto modelo de ordenación territorial a sus órganos representativos, quienes habrán de tener en cuenta las alegaciones y sugerencias como una posibilidad más entre otras ${ }^{58}$. De manera que es a la Administración a quien en última instancia le corresponde decidir, tanto porque posee una visión global de los problemas del territorio de la que carecen los ciudadanos, como por estar sometida constitucionalmente a velar por el cumplimiento de los intereses generales.

Existe una frondosa jurisprudencia del TS y de los TSJ de las Comunidades Autónomas dedicada a fijar los contornos de la participación ciudadana en el trámite de exposición al público de los trabajos preparatorios de los planes, la calificación jurídica de dicha exposición pública y los efectos de su omisión. Hay que tener en cuenta que, con carácter

\footnotetext{
57 STS de 13 de octubre de 1988, Ar. 8216, F.D. $3^{\circ}$ de la Sentencia apelada, (J García Estartús, PGOU de San Andrés del Rabanedo). En esta ocasión los vecinos habían presentado 78 sugerencias que fueron contestadas por el equipo redactor. La sentencia tiene su origen en la rescisión unilateral por la Administración Local del contrato celebrado con un arquitecto que se había comprometido a revisar el PGOU en el plazo de 10 meses. Posteriormente el Ayuntamiento desistió de los trabajos realizados.

58 STS de 11 de marzo de 1991, Ar. 1982, F.D. $7^{\circ}$ (F.J. Delgado BarRio, Normas Subsidiarias de Flaça). En fecha temprana, García de Enterría ya había puesto de relieve que, sin perjuicio de las funciones positivas que proporcionaba la participación ciudadana a través de entidades asociativas voluntarias o privadas, el juicio y opinión de los representantes municipales debía tener un valor prevalente, vid. «Los principios de la organización del urbanismo», op. cit., p. 395.
} 
general, los procesos jurisdiccionales en esta materia se articulan, en lo que aquí interesa, sobre la pretensión de declarar la nulidad del plan por el incumplimiento por parte de la Administración municipal de la apertura del reiterado trámite de exposición pública de los trabajos previos del plan. En las páginas que siguen vamos a examinar la jurisprudencia recaída sobre esta materia, destacando la existencia de dos corrientes jurisprudenciales contradictorias sobre el alcance y efectos de dicha información pública, cuyos aspectos más relevantes, y en apurada síntesis, pasamos a exponer.

Una primera línea jurisprudencial, mayoritaria y perfectamente consolidada, considera que la omisión del trámite de exposición pública de los trabajos preparatorios no implica la anulación del plan impugnado, quedando a salvo la garantía de intervención de los particulares por la existencia de dos trámites más de información y exposición al público -tras las aprobaciones inicial y provisional respectivamente- en el procedimiento formal de elaboración de los instrumentos urbanísticos. En efecto, desde fecha temprana, el TS ha entendido que no es obligatorio el reiterado trámite de información pública en esta fase preliminar porque, al tener la misma finalidad que la información pública de apertura obligatoria tras la aprobación inicial, cómo es procurar la intervención de los interesados al objeto de que formulen reparos o sugerencias o propongan soluciones alternativas, dicha intervención se cumple satisfactoriamente cuando, «por el incumplimiento del primero de dichos artículos no pudieron participar [art. $125 \mathrm{RPU}$, pero si lo hicieron al cumplirse el segundo [art. $128 \mathrm{RPU}$ ], sin limitación alguna, para procurar la protección de sus derechos o intereses o el éxito de sus particulares criterios» ${ }^{59}$.

Abundando en esta doctrina de diferir la efectividad de la participación ciudadana al trámite de información pública que se inicia tras la aprobación inicial del plan, esto es al ámbito del procedimiento administrativo formal, la STS de 15 de julio de $1995^{60}$ consagra una delimitación funcional entre aquél y la exposición al público de los trabajos preliminares. Así, concibe que mientras esta última tiene como finalidad formular sugerencias o alternativas, la información pública, por su parte, «proporciona actitudes más concretas y beligerantes respecto al Plan» como son las alegaciones, que habrán de deducirse por las partes interesadas o afectadas ya dentro del expediente administrativo.

59 STS de 6 de abril de 1987, Ar. 4237, F.D. $3^{\text {o }}$ (J.M a . REYes Monterreal, PGOU de Aiguadreda).

60 STS de 15 de julio de 1995, Ar. 5855, F.D. $6^{\circ}$ (P. Esteban Álamo, Revisión del PGOU de Ávila). 
De suerte que la imposibilidad de formular sugerencias por parte de los ciudadanos a los trabajos preliminares del plan por la falta de apertura del periodo de exposición pública, queda subsanada por el hecho de que el ejercicio de ese derecho se pospone a la fase formal del procedimiento de elaboración de aquéllos. A nuestro modo de ver, esta concepción del trámite de actuaciones previas limita en exceso las facultades de intervención de los particulares, si tenemos en cuenta que, en la práctica, las alegaciones son sistemáticamente rechazadas.

Por su parte, los TSJ de las Comunidades Autónomas han acogido mayoritariamente esta doctrina, reiterando alguno de los argumentos empleados por el TS e introduciendo nuevos elementos de juicio. Así, en primer lugar, se ha afirmado que el trámite de la fase previa referido a la información o encuesta pública previsto en el art. 125.1 RPU, al no estar recogido en la Ley del Suelo de 1976 y no ser preceptivo de acuerdo con el texto del art. 116 RPU, tiene carácter facultativo y su omisión no puede traer consigo nulidad de ninguna clase, «ya que lo verdaderamente importante es el acuerdo de someter el expediente al trámite de información pública después de la aprobación inicial», con lo que queda ampliamente cumplida la exigencia legal de participación ciudadana en la elaboración del planeamiento ${ }^{61}$.

En segundo término, y en lógica coherencia con la tesis acabada de exponer, se entiende que la omisión de dicho trámite carece de fuerza invalidatoria en los supuestos en que se aprecie que la emisión de sugerencias ha quedado subsanada por el resultado del trámite de información pública posterior a la aprobación inicial prevista en el art. $128 \mathrm{RPU}^{62}$. Abundando en esta tesis, la STSJ del País Vasco de 28 de junio de 2002, en un supuesto en el que el plazo de exposición al público de los trabajos preparatorios había sido menor al mínimo de treinta días, afirma que no

\footnotetext{
${ }^{61}$ SSTSJ de Canarias, n. ${ }^{\circ}$ 527/2001, de 31 de mayo, RJCA 2001/824, F.D. $1^{\circ}$ (A. AcEVEDO y CAMPOS, Modificación del articulado de las normas urbanísticas del PGOU de Santa Cruz de La Palma); y de La Rioja de 19 de mayo de 1995, Ar. 1995/302 (V. DE LA IgLeSIA DuARTE, Revisión-Modificación del PGOU de Logroño).

62 STSJ de Cataluña núm 1063/2000, de 15 de diciembre, RJCA 2001/196, F.D. $2^{\circ}$ (J. JuANOLA SOLER). En esta ocasión los propietarios recurren la resolución del Consejero de Política Territorial y Obras Públicas de la Generalidad por la que se aprobó definitivamente la modificación del PGOU de la Comarca de Sabadell en el Sector del casco antiguo de Barberà del Vallès. Esta sentencia añade un elemento más de juicio, como es la necesidad de que en el proceso jurisdiccional se acredite en la fase de prueba que los demandantes formularon alegaciones en el trámite de exposición pública posterior a la aprobación inicial. En igual sentido, SSTS de 10 de junio de 1997, AR. 5028 (M. V. Garzón Herrero, Normas Complementarias de Planeamiento del Plan General de Ordenación Urbana de Bilbao y su Comarca referentes al municipio de Portugalete); y de 7 de mayo de 1998, Ar. 3619 (J. RodRíGUEZ-ZAPATA, Plan Especial de la Villa Olímpica de Bañolas).
} 
se puede oponer ningún vicio de nulidad a tal circunstancia por el hecho de que el Ayuntamiento había recibido, y posteriormente contestado, alegaciones extemporáneas ${ }^{63}$.

En tercer lugar, se ha puesto de relieve la naturaleza meramente facultativa de este trámite al afirmar que la realización de las encuestas o debates previos establecidos en el reiterado art. 125 RPU no excluye el trámite de información pública que ha de seguir siempre a la aprobación inicial del proyecto, «ni limita tampoco las posibilidades de los ciudadanos a través del mismo, ni la posibilidad que tiene la Administración de introducir rectificaciones en función de los resultados» ${ }^{64}$.

Avanzando un paso más en esta estricta jurisprudencia, podemos mencionar, en último término, la STSJ de Cataluña de 2 de febrero de 2001, que, ante un supuesto en el que se había acordado abrir el periodo de información pública no produciéndose la publicación efectiva de alternativa o de síntesis alguna, afirma categóricamente que ello no puede suponer causa de nulidad del citado trámite, «pues no impide que la información pública cumpla con la finalidad que le es propia (favorecer la participación ciudadana en la elaboración de los planes) $\rangle^{65}$.

Paralelamente a esta doctrina mayoritaria, cabe apuntar la existencia de otra línea jurisprudencial, contradictoria con la anterior, que se muestra más generosa en la delimitación de la participación ciudadana en este trámite inicial de elaboración del planeamiento y, en consecuencia, más rígida con los efectos que se anudan a la omisión de la exposición pública de los trabajos preparatorios del plan. Con carácter preliminar, cabe señalar cómo, a diferencia de las Sentencias comentadas en párrafos anteriores, la STS de 8 de abril de 1989 proclama el carácter necesario de la exposición pública de los trabajos previos en los supuestos de Planes Generales, Nor-

\footnotetext{
${ }^{63}$ En palabras de la propia Sentencia, «no podemos olvidar [que] el procedimiento de elaboración es singularmente participativo, no sólo con carácter previo al avance, sino con posterioridad al mismo tras la aprobación inicial así como provisional, ambas en sede del Ayuntamiento de Iruña de Oca, lo que ha de quitar relevancia anulatoria a la deficiencia o error cometido por el Ayuntamiento». STSJ del País Vasco, núm. 673/2002, de 28 de junio, Ar. 2003/97820, F.D. $4^{\circ}$ (A. Ruiz RuIz, Revisión de Normas Subsidiarias de Iruña de Oca).

${ }^{64}$ STSJ de Murcia, n. ${ }^{\circ}$ 358/2003, de 23 de octubre, Ar. 2003/1089, F.D. $3^{\circ}$ (L.F. AlCÁZAR VIEYRA DE ABREU). Supuesto en el que los propietarios habían recurrido el acuerdo plenario de aprobación definitiva de un Plan Especial de Reforma Interior, solicitando que se anulase el acuerdo en el que se aceptaron las sugerencias recibidas como consecuencia del Avance y que adoptaba como opción de desarrollo la propuesta efectuada por el equipo redactor.

${ }^{65}$ STSJ de Cataluña, n. ${ }^{\circ}$ 102/2001, de 2 de febrero, RJCA 2001/689, F.D. $2^{\circ}$ (D.T. BERBERofF AyUdA, Revisión de las Normas Subsidiarias de la Pobla de Segur).
} 
mas Subsidiarias y Complementarias de Planeamiento y de ciertas clases de Planes Especiales de Reforma Interior ${ }^{66}$. El TS funda la naturaleza obligatoria de dicha exposición pública, en el caso de los instrumentos de planeamiento general, mediante el argumento de que «la intensificación de la participación ciudadana tiene su razón de ser en que se trata de elegir un modelo territorial general como marco de convivencia»; mientras que, en el supuesto de los Planes Especiales, la publicación de tales trabajos resulta necesaria si «afectan a barrios consolidados incidiendo sobre su población», pues se trataría de llevar a cabo «intervenciones quirúrgicas que afectan a un cuerpo vivo, a una población que puede verse desplazada por la remodelación proyectada» ${ }^{67}$.

Como se observa, el TS vincula la obligatoriedad de exponer al público los trabajos preparatorios de los instrumentos de planeamiento en función del objeto de éstos y su incidencia en el ámbito personal de los afectados. En efecto, tanto la elección de un modelo territorial general que opere como marco de convivencia de la sociedad, como las propuestas de ordenación de ámbito territorial limitado, poseen la suficiente importancia para el desarrollo de la comunidad como para que la exposición pública de los trabajos técnicos preliminares sea obligatoria a fin de que los ciudadanos puedan formular las sugerencias que estimen pertinentes.

Junto a esta proclamación de la necesidad de exposición pública de los trabajos previos, la STS de 15 de enero de 2000 avanza un paso más hacía el reforzamiento de la participación ciudadana en esta fase procedimenta $1^{68}$. En su extenso F.D $3^{\circ}$ contiene una doctrina, a nuestro juicio, ejemplar por su decidida vocación garantista de la participación ciudadana en el proceso de elaboración de los instrumentos de ordenación urbana. En concreto, la Sentencia de referencia resuelve en sentido negativo el recurso de casación promovido por la Comunidad Foral de Navarra contra una Sentencia del Tribunal Superior de Justicia de Navarra que, estimando el recurso contencioso-administrativo interpuesto por dos entidades mercantiles contra la Orden Foral por la que se aprobó definitivamente la modi-

\footnotetext{
${ }^{66}$ STS de 8 de abril de 1989, Ar. 3452, (F.J. Delgado BARRIO, aprobación definitiva del Plan Especial de Reforma Interior de Carlet). No obstante hay que tener en cuenta que el TS rechaza el recurso interpuesto porque el Plan litigioso no alteraba unas alineaciones reales, circunstancia «que hace innecesario determinar las consecuencias jurídicas a derivar de la vulneración de lo establecido en dicho precepto [art. 125.1 RPU]».

${ }^{67}$ Doctrina que, con relación a los Planes Especiales de Reforma Interior, es reiterada por nuestro TS. A título de ejemplo, puede verse la STS de 17 de marzo de 1992, Ar. 3275, F.D.3º (MARIANO DE ORO-Pulido y LóPEZ, Aprobación de Plan Especial de Ordenación del Sector delimitado por las calles Tarragona, Diputación, Vilamaría y Gran Vía de las Cortes Catalanas, de Barcelona).
}

${ }^{68}$ STS de 15 de enero de 2000, Ar. 471 (Ricardo EnRíquez SANCHO). 
ficación de las Normas Subsidiarias y Complementarias de Planeamiento de Pamplona y de su zona de influencia, anuló dicha Orden por haberse omitido en su elaboración el trámite de exposición al público de los trabajos preparatorios, conforme a lo prescrito en el art. 125.1 RPU, así como por haberse prescindido del Estudio económico-financiero exigido por la normativa foral aplicable a los Planes Generales y Normas Subsidiarias de Planeamiento.

En lo que ahora importa, los pilares sobre los que se asienta la doctrina de la Sentencia pueden sintetizarse de la siguiente manera. En primer lugar, ante la pretendida alegación autonómica de que el trámite de información pública prevista en el art. 116.1 RPU es potestativo y, por ello, su omisión no supondría la nulidad del concreto instrumento de planeamiento, el TS pone de manifiesto la confusión procedimental que preside tal argumentación al estar referida a una figura que no es de aplicación al supuesto de hecho. En efecto, tal y como previene el propio Tribunal, en el caso de referencia no estaríamos en presencia de la fase de información pública, previa a cualquier acuerdo de elaboración del plan, «que tiene carácter facultativo y la finalidad de recoger sugerencias u observaciones sobre la necesidad, conveniencia y demás circunstancias de la ordenación» sino, por el contrario, ante la obligación de exponer al público los trabajos de confección del plan, exigida por el art. 125.1 RPU, con el fin de que cualquier persona pueda formular sugerencias o alternativas a las reflejadas en los trabajos ya realizados ${ }^{69}$. De modo que, la exposición al público de los trabajos preliminares se configura como un deber de la Administración urbanística competente y no como una mera facultad disponible por la misma. Este carácter obligatorio tiene una consecuencia de primera magnitud, por lo que respecta a su eventual omisión tal y como veremos a continuación.

El segundo aspecto sobre el que incide la doctrina de la Sentencia comentada radica en delimitar la función que corresponde al reiterado art. 125.1 RPU y, correlativamente, los efectos de su posible omisión. En este sentido, el TS rechaza que la ausencia del trámite de información pública de los trabajos previos sea una causa de anulabilidad, tal y como pretendía la Comunidad Autónoma, sino que, por el contrario, entiende que se trata de una causa de nulidad de pleno derecho. A diferencia de otras fallos jurisprudenciales vistos con anterioridad, el propio Tribunal niega que la posibilidad de formular alegaciones tras la aprobación definitiva del plan pueda subsanar

\footnotetext{
${ }^{69}$ Precepto que «en su teleología busca respetar el derecho al procedimiento administrativo (presente en éste como en tantos otros casos por la propia intervención de la Carta Magna, en la previsión de su artículo 9.2 «in fine»)», STSJ de La Rioja, n. ${ }^{\circ}$ 504/2000, de 31 de julio, F.D. $6^{\circ}$ (J.I. RuIZ de Palacios Villaverde, Revisión del PGOU de Logroño).
} 
la omisión de la exposición de los trabajos preliminares, porque en esta fase, y aquí entendemos que radica la importancia de la Sentencia, «no se trata propiamente de la defensa de intereses particulares afectados sino de hacer efectivo el derecho de participación ciudadana reconocido en el art. 4.2 TRLS. [...] La cuestión no es, pues, si los recurrentes en la instancia han sufrido o no indefensión, puesto que formularon alegaciones en la fase formal de información pública, sino si la infracción cometida ha impedido alcanzar el fin propuesto con el trámite omitido, que es el de la elaboración de las Normas con la más amplia participación ciudadana».

Tal y como se infiere del párrafo transcrito, el TS deslinda perfectamente el derecho de los particulares a formular alegaciones toda vez que se ha aprobado inicialmente el concreto instrumento de planeamiento, de la exigencia constitucional -arts. 9.2, 105.a)- de que todos los ciudadanos participen en la elaboración de disposiciones generales incluso, desde antes de adoptarse acuerdo municipal alguno al respecto. Con ello, las posibilidades de actuación de los ciudadanos, aportando sugerencias a los trabajos preparatorios, adquiere especial importancia en cuanto que la Administración aún no se ha pronunciado sobre la preferencia de ninguna de las opciones posibles, materializándose en la práctica el debate social que debe presidir la confección de los planes urbanísticos desde su formulación inicial.

Además, esta interpretación pone de manifiesto que la elección del concreto modelo territorial plasmado en el plan no puede sustraerse a la comunidad ni diferir su discusión a un momento posterior a la aprobación inicial, pues, tal y como se ha venido a resaltar, «su eventual rechazo en este último caso se traduciría en una inútil pérdida de tiempo y en un mayor encono de las diversas posiciones al respecto» ${ }^{70}$.

Esta doctrina va a tener solución de continuidad, entre otras, en la STS de 23 de enero de 2003, que la aplica a un supuesto de aprobación definitiva de modificación de un Plan Especial de Reforma Interior ${ }^{71}$. Dicha Sentencia resuelve un recurso de casación promovido por la Generalidad de Cataluña contra una Sentencia del Tribunal Superior de Justicia de Catalu-

\footnotetext{
${ }^{70}$ Cfr., J.A. LóPEZ PelLicer: Elaboración y gestión en el planeamiento urbanístico (Intervención de los particulares), Montecorvo, Madrid, 1983, p. 89. Por otra parte, esta concepción de la participación ciudadana en la fase inicial de elaboración de los instrumentos de planeamiento, como tendremos ocasión de ver en el epígrafe siguiente, enlaza con la doctrina reiterada por el TS de que las alegaciones de mera oportunidad formuladas ante la Administración durante la tramitación del procedimiento administrativo podrían tener fuerza bastante para alterar el modelo inicialmente elegido y que, sin embargo, alegadas ante los Tribunales devienen inoperantes, pues éstos no pueden decidir con criterios de oportunidad sobre las determinaciones del plan sino, exclusivamente, de acuerdo con estrictos criterios jurídicos.
}

${ }^{71}$ STS de 23 de enero de 2003, Ar. 961 (Pedro José Yagüe GiL). 
ña que anuló las resoluciones de la Consejería de Política Territorial y Obras Públicas que, estimando diferentes recursos de reposición, dejaron sin efecto el acuerdo de la Comisión de Urbanismo de Barcelona aprobatorio de la modificación del Plan Especial de Reforma Interior de Enlace de la Rambla con la calle Rull, ordenando la retroacción de actuaciones al momento de exposición al público de los trabajos preliminares para que los particulares pudieran formular sugerencias previas a la aprobación inicial.

Además de los argumentos expuestos al comentar la anterior Sentencia, que reproduce literalmente en su F.D. $5^{\circ}$, este fallo añade alguna precisión en función de la naturaleza de la figura de planeamiento que tiene por objeto. En efecto, al tratarse de la modificación de un Plan Especial que se proponía mediante el ejercicio de la iniciativa privada -la Universidad Pompeu Fabra-, entiende el Tribunal que el trámite de sugerencias previas juega con mayor intensidad. Y ello, porque no existe argumento alguno para suponer que las sugerencias del promotor sean mejores, o más acordes con el interés urbanístico, que cualesquiera de las sugerencias que los ciudadanos puedan formular, lo que conlleva el riesgo de que «el Ayuntamiento asuma sin más el proyecto de un particular en cuyo ánimo puede estar quizás más (aunque quizás no) el propio beneficio que el interés público» (F.D. $6^{\circ}$ ).

Recapitulando lo expuesto hasta el momento, podemos concluir afirmando el carácter limitado de la participación ciudadana en la fase previa a la tramitación administrativa del plan que se deduce de la jurisprudencia reseñada en páginas anteriores. Así, salvo las sentencias comentadas en último lugar, la línea jurisprudencial mayoritaria se ha mostrado, en términos generales, muy poco propicia a favorecer la intervención de la comunidad vecinal en dicha fase. Diferir la posibilidad de formular alegaciones o sugerencias, hurtando un debate social previo indispensable, a la tramitación formal de los planes toda vez que se abren los periodos de información pública, después de las aprobaciones inicial y provisional, resulta un bagaje ciertamente escaso para que el plan alcance la legitimidad democrática que se predica de la participación ciudadana.

\section{LA PARTICIPACIÓN CIUDADANA COMO MECANISMO DE CONTROL DE LA ACTIVIDAD DEL PLANIFICADOR. LAS «MODIFICACIONES SUSTANCIALES» DEL PLANEAMIENTO: CONCEPTO, DELIMITACIÓN Y EFECTOS}

La última manifestación de la participación ciudadana en el proceso de elaboración de los planes urbanísticos que vamos a examinar, se produce 
con ocasión de las informaciones públicas que se abren tras las aprobaciones inicial y provisional de dichos planes. Se trata, por tanto, de la intervención ciudadana en el procedimiento administrativo formal de elaboración de una disposición de carácter general. Es por ello, que en los casos en que se produce su omisión o realización defectuosa lleva implícita la nulidad del plan de que se trate ${ }^{72}$, a diferencia de lo que ocurre con la ausencia de exposición al público de los trabajos previos de los planes, tal y como hemos tenido ocasión de ver en el epígrafe anterior. Delimitando un poco más el objeto de análisis, debemos hacer notar que el grueso de la jurisprudencia que tanto el TS como los TSJ de las Comunidades Autónomas han dictado sobre participación ciudadana en el reiterado proceso de elaboración de planes de urbanismo se centra en los supuestos de introducción por la Administración urbanística de modificaciones en las determinaciones del planeamiento tras las aprobaciones inicial, provisional y definitiva y la obligatoriedad de abrir un nuevo periodo de información pública en tales casos.

En este sentido resulta procedente advertir que, además de que en ningún precepto legal se establece una prohibición expresa para que las Corporaciones Locales o, en su caso, el órgano correspondiente de las Comunidades Autónomas introduzcan modificaciones puntuales en los instrumentos de planeamiento con ocasión de su aprobación definitiva, la lógica interna de la naturaleza de éstos tampoco lo impide. Es decir, el proyecto de plan no es un documento pétreo que resulte intocable durante su tramitación administrativa hasta convertirlo en definitivo. Por el contrario, posee una naturaleza dinámica que puede verse afectada por circunstancias sobrevenidas no tenidas en cuenta en el momento de su aprobación inicial ${ }^{73}$. De modo que la Administración urbanística, en el ejercicio del ius variandi del que es titular, puede introducir alteraciones con respecto al proyecto inicialmente aprobado siempre que obedezcan a nuevas necesidades surgidas durante la tramitación del mismo, exigiendo en todo caso una adecuada motivación que las justifique ${ }^{74}$.

\footnotetext{
72 Así, por ejemplo, S. MuÑoz Machado: «El Planeamiento Urbanístico», en S. MuÑoz Machado (dir.), Tratado de Derecho Municipal, II, $2^{\mathrm{a}}$ ed., Civitas, Madrid,2003, pp. 2199-2200.

73 En este sentido, la STS de 3 de mayo de 1996, Ar. 3848, F.D. $5^{\circ}$ (P.J. YAGÜE GIL, PGOU de MURO). Con anterioridad, la STS de 10 de julio de 1991, Ar. 6291, F.D. $4^{\circ}$ (M. PASTOR LÓPEZ, PGOU de Lloret de Mar), afirmaba que las modificaciones introducidas en el trámite de aprobación definitiva constituían el ejercicio de la potestad innovadora o ius variandi de la Administración, que «es inherente a la función reglamentaria y planificadora, derivando del carácter dinámico del propio planeamiento y a la necesidad de adaptación a las exigencias cambiantes de la realidad, así como a la naturaleza estatutaria del derecho de propiedad inmobiliaria urbana, en la que no se dan derechos adquiridos derivados del Plan anterior».

${ }^{74}$ STS de 26 de mayo de 1997, Ar. 5919, F.D. $4^{\circ}$ (J.M. SANZ BAYÓn, PGOU de Villafranca del Penedés).
} 
De acuerdo con estas premisas, en los siguientes epígrafes vamos a referirnos, en apurada síntesis, a determinar el fundamento de esa nueva información pública que ha de abrirse cuando se introduzcan modificaciones sustanciales en los planes aprobados definitivamente; seguidamente examinaremos qué entiende el TS por tales modificaciones sustanciales para, a continuación, enumerar someramente algunas de las determinaciones que la jurisprudencia ha considerado como modificaciones sustanciales; y en última instancia expondremos los efectos que conlleva la declaración de que una determinada modificación tenga la condición de sustancial para el plan de que se trate.

\section{1. La participación ciudadana como título habilitante de la nueva información pública cuando se introducen «modificaciones sustanciales»}

Desde la entrada en vigor de la Constitución en 1978 y con las previsiones contempladas en el RPU ${ }^{75}$, la jurisprudencia se ha mostrado firmemente favorable a exigir, como presupuesto indispensable de la validez de las posibles modificaciones sustanciales introducidas en un Plan por el órgano competente para su aprobación definitiva, el previo sometimiento a una nueva información pública. Su justificación se basa en que, no sólo entra en juego la protección que deben merecer los intereses privados sino, sobre todo, «para garantizar la mayor participación ciudadana en el proceso de su elaboración y para evitar que la aprobación definitiva del Plan pudiera convertirse en una imposición arbitraria o injustificada de la Administración ${ }^{76}$. De manera que en los casos en que

\footnotetext{
75 Téngase en cuenta que tras la entrada en vigor del RPU se publicaron las denominadas Instrucciones de la Dirección General de Urbanismo sobre participación pública, información y publicidad del planeamiento urbanístico, que preveían en su punto 24 que en el caso de modificaciones sustanciales, «el órgano competente deberá asegurar la mayor difusión del planeamiento y participación de los interesados», adoptando, en su caso, las medidas previstas en el apartado 22 relativas a la descripción de la participación y sus resultados -obligación de que la Memoria del Plan incluyese una descripción de la metodología adoptada de participación pública, reseñando las reuniones celebradas, la formación de grupos de trabajo, charlas, coloquios, medios de propaganda utilizados para incitar la intervención popular, modificaciones introducidas, etc.-. Su texto puede consultarse en J.A. LóPEZ Pellicer, op.cit., pp. 96-112.

${ }^{76}$ Entre otras, SSTS 29 de noviembre de 1989, Ar. 8373, F.D. $3^{\circ}$ (M. DE Oro-Pulido y LóPEZ, PGOU de Sagunto); 27 de noviembre de 1991, Ar. 9295, F.D. $2^{\circ}$; y, 24 de septiembre de 1991, Ar. 6972, F.D. $3^{\circ}$ (M. de Oro-Pulido y LóPEz, PGOU de Girona). Fenómeno del que se ha hecho eco la Memoria Anual del Defensor del Pueblo 2003, al constatar que son reiteradas las quejas de los ciudadanos en las que alegan que las Administraciones Públicas incorporan a lo largo de la tramitación de los instrumentos de planeamiento modificaciones que alteran de manera esencial el modelo territorial que en su día fue expuesto al público.
} 
se omite dicho trámite se produce no sólo la vulneración del procedimiento administrativo de elaboración de una disposición general, sino también se conculca el mandato de participación contenido en la legislación urbanística ${ }^{77}$, que encuentra su fundamento constitucional en los arts. 9.2 y $105 . \mathrm{a})$.

Asimismo, en alguna ocasión, se ha extendido dicha exigencia no sólo a las modificaciones incorporadas después de las aprobaciones inicial, provisional y definitiva, sino también a las introducidas por vía de recurso, dado el carácter esencial de la información pública y la situación de indefensión que ocasiona su omisión a los ciudadanos ${ }^{78}$.

Tal y como se infiere de lo expuesto es, precisamente, la importancia de la participación ciudadana, unido a los fines ordenadores de la ciudad consustanciales del plan, los que determinan la necesidad de reiterar el trámite de información pública cuando se introducen ese tipo de modificaciones. Desde esta perspectiva, la participación se configura como un mecanismo de control ciudadano de la discrecionalidad de los órganos que tienen encomendada la aprobación definitiva de los diferentes planes de urbanismo. Pero, además, tal y como ha señalado Delgado Barrio, su omisión privaría a los ciudadanos de formular toda una serie de alegaciones que «durante la tramitación del procedimiento podrían tener fuerza convincente bastante para alterar el modelo inicialmente elegido y que, sin embargo, ante una Sala de lo Contencioso-Administrativo resultarán inoperantes, dado que ésta no puede decidir con criterios de oportuni$\operatorname{dad} »^{79}$.

Concretado sucintamente el fundamento que determina la necesidad de abrir una nueva fase de información pública cuando se han introducido modificaciones sustanciales en el plan después de su aprobación definitiva, corresponde a continuación determinar qué entiende el TS por tales modificaciones.

\section{2. La delimitación jurisprudencial del concepto}

Desde fecha temprana, el TS ha ido perfilando los contornos de qué debía entenderse por «modificaciones sustanciales» al efecto de exigir un

\footnotetext{
77 En este sentido, se manifiesta la STS de 12 de noviembre de 1998, Ar. 9597, F.D. $3^{\circ}$ (precitada).

${ }^{78}$ STS de 29 de noviembre de 1989 (precitada).

${ }^{79}$ Cfr. J. Delgado Barrio: El control de la discrecionalidad del planeamiento urbanístico, Civitas, Madrid, 1993, pp. 58-59.
} 
nuevo periodo de información pública para que los ciudadanos pudiesen formular las sugerencias que estimasen oportunas sobre las nuevas determinaciones. Valga recordar en este sentido que está firmemente consolidada en la jurisprudencia la noción de que estamos en presencia de un concepto jurídico indeterminado que no puede ser definido apriorísticamente, siendo preciso determinarlo en cada caso concreto por el propio órgano jurisdiccional de acuerdo con su contenido, la entidad de sus modificaciones y su funcionalidad ${ }^{80}$. De modo que sólo serán calificados de sustanciales los cambios «que impongan un nuevo esquema de planeamiento, alterando de manera importante o esencial las líneas o criterios básicos del Plan, y su propia estructura», esto es, que alteren el esquema fundamental de planeamiento afectando sustancialmente al modelo territorial dibujado por el propio Plan ${ }^{81}$.

Además, los cambios operados en el Plan por la introducción de las modificaciones deben suponer la alteración del planeamiento elegido inicialmente hasta el extremo de hacerlo distinto y no solamente diferente en aspectos puntuales y accesorios ${ }^{82}$. Razón por la cual la determinación de la existencia o no de una modificación sustancial debe efectuarse desde la perspectiva del plan en su conjunto ${ }^{83}$, y no por el hecho de que un determinado propietario haya sufrido una concreta y específica alteración en un ámbito de su propiedad. Más concretamente ${ }^{84}$, la comparación ha de efectuarse tomando como parámetro el modelo provisionalmente aprobado, contrastado con el que es objeto de aprobación definitiva y, en ningún caso, entre los terrenos de los propietarios afectados y el plan, porque en ese supuesto será muy difícil que se puedan estimar las modificaciones.

Para el cumplimiento de tal fin, resulta insoslayable la práctica de la oportuna prueba pericial a través de los correspondientes informes técnicos que, de modo fehaciente, pongan de manifiesto que las determinaciones introducidas en el proyecto suponen una alteración del Plan en los tér-

\footnotetext{
${ }^{80}$ STS de 10 de julio de 1991, Ar. 5746, F.D. $2^{\circ}$ de la Sentencia apelada asumido por el TS (P. EsTEBAN ÁlAMO, PGOU de Cabrera del Mar).

${ }^{81}$ STS de 10 de julio de 1991, Ar. 6291, F.D. $2^{\circ}$, precitada, con cita de Sentencias anteriores; argumento reiterado de modo constante por el TS, por ejemplo, en SSTS de 15 de diciembre de 1992, Ar. 9834(F.J. Delgado Barrio, PGOU de Lloret de Mar); 22 de mayo de 1995, Ar. 3807, F.D. $2^{\circ}$ (P. Esteban Álamo, PGOU de Lloret de Mar); 13 de junio de 1995, Ar. 4951, F.D. $2^{\circ}$ (J. Barrio Iglesias, PGOU de Las Rozas); 23 de abril de 1996, Ar. 3267, F.D. $2^{\circ}$ (J. BARRIO IgLESIAs, PGOU de Las Rozas).

82 STS de 23 de marzo de 1993, Ar. 2524, F.D. $2^{\circ}$ (J. BARRio IgLESIAS, PGOU de Mollet del Vallès).

${ }^{83}$ STS de 12 de febrero de 1996, Ar. 963, F.D. $2^{\circ}$ (M.V. Garzón Herrero, PGOU de Las Rozas).

${ }^{84}$ STS de 31 de enero de 2000, Ar. 581, F.D. $2^{\circ}$ (M.V. Garzón Herrero, PGOU de Alcanar).
} 
minos descritos en los párrafos anteriores ${ }^{85}$. De manera que, en el supuesto de inexistencia de los citados informes técnicos, que acrediten el pretendido carácter sustancial de la modificación de que se trate, no procederá la apertura de un nuevo periodo de información pública ni, por lo tanto, la retroacción del procedimiento ${ }^{86}$.

De acuerdo con la configuración que del concepto de modificaciones sustanciales ha delimitado el TS, a los solos efectos enunciativos, podemos enumerar sucintamente la modificación de algunas determinaciones de planeamiento que el Tribunal ha considerado que no se incardinan dentro de tal concepto. Entre ellas, y siguiendo la enumeración que contiene la STS de 4 de mayo de $1999^{87}$, podemos señalar las siguientes: la delimitación de la clasificación de suelo, ampliando o excluyendo las diferentes clases del mismo ${ }^{88}$; la alteración del uso del suelo en una determinada zona ${ }^{89}$; la minoración del aprovechamiento total de Suelo Urbanizable, disminuyendo por ello las unidades de aprovechamiento y la edificabilidad $^{90}$; la reordenación de unidades de actuación y de volúmenes entre zonas concretas ${ }^{91}$; la modificación de la anchura y alineaciones en una calle determinada ${ }^{92}$; la elaboración del Catálogo de Edificios; y, por últi-

${ }^{85}$ Entre otras, SSTS de 12 de noviembre de 1998, Ar. 9597, F.D. $5^{\circ}$ (J. RodríGUEZ-ZAPATA, PGOU de Vilassar de Mar); y, 31 de enero de 2000, Ar. 581, F.D. $2^{\circ}$ (precitada).

${ }^{86}$ SSTS de 17 de abril de 2001, Ar. 3678, F.D. $5^{\circ}$ (J.M. SANZ BAYÓN, PGOU de Paterna); 30 de abril de 2001, Ar. 3687 , F.D. $3^{\circ}$ (M.V. Garzón Herrero, PGOU de Paterna); y STSJ de Cataluña n. ${ }^{\circ}$ 1232/2000, de 27 de diciembre, RJCA 2001/297, F.D. $4^{\circ}$ (D.T. Berberoff Ayuda, Plan Especial de la Riera de Canadell de Palafrugell).

${ }^{87}$ STS de 4 de mayo de 1999, Ar. 3406, F.D. $5^{\circ}$ (M. V. Garzón Herrero, PGOU de Málaga).

${ }^{88}$ En igual sentido, las SSTS de 8 de mayo de 1996, Ar. 3857, F.D. $2^{\circ}$ (J. BARRIO IgLESIAS, PGOU de Las Rozas); 17 de junio de 1997, Ar. 5460, F.D. $5^{\circ}$ (M.V. Garzón Herrero, Normas Subsidiarias de Níjar); 13 de octubre de 1999, Ar. 7961, F.D. $3^{\circ}$ (J. RodRíGUEZ-ZAPATA, PGOU de Laredo); y STSJ de Cataluña n. ${ }^{\circ} 1188 / 2001$, de 30 de noviembre, RJCA 2002/529, F.D.3 ${ }^{\circ}$ (M M $^{\text {.P. MARTíN Cos- }}$ COLLA, revisión del PGOU de Mataró).

89 STS de 12 de febrero de 1996, Ar. 963, F.D. $3^{\circ}$ (M.V. Garzón Herrero, PGOU de Las Rozas).

90 SSTS de 13 de junio de 1995, Ar. 4951, F.D. $3^{\circ}$ (J. BARRIo IgLESIAS, PGOU de Las Rozas); y 20 de diciembre de 2002, Ar. 229, F.D. $2^{\circ}$ (Ricardo Enríquez SANCHo, Normas Subsidiarias de Las Quintanillas).

91 Asimismo, las SSTS de 20 de octubre de 1997, Ar. 7501, F.D. $5^{\circ}$ (J.M. SANZ BAYÓN, PGOU de Marbella); 27 de febrero de 1995, Ar. 1082, F.D. $3^{\circ}$ (P. Esteban Álamo, modificación de PGOU de Mataró); y, 23 de junio de 1994, Ar. 5339, F.D. $3^{\circ}$ (F.J. Delgado BarRio, Revisión y adaptación del PGOU de Suances).

92 Igualmente, SSTS de 23 de abril de 1997, Ar. 2790, F.D. $5^{\circ}$ (P.J. YAGÜE GIL, modificación del PGOU de Albacete); y, 5 de junio de 1995, Ar. 4941, F.D. $2^{\circ}$ (J.M. SANZ BAYÓN, revisión y adaptación del PGOU de Capellades). 
mo, la modificación o supresión de aspectos puntuales de las Normas y Ordenanzas $^{93}$.

\section{3. Supuestos de nuevas determinaciones que se consideran «modificaciones sustanciales»}

Tal y como hemos expuesto en líneas precedentes, sólo aquellas modificaciones que supongan un nuevo esquema de planeamiento, alterando de modo esencial las líneas básicas o criterios del plan inicialmente aprobado y afectando al modelo territorial dibujado, son susceptibles de ser calificadas como sustanciales a los efectos de requerirse la apertura de un nuevo periodo de información pública con la finalidad de que los particulares puedan formular las alegaciones que estimen pertinentes. De manera que, con carácter meramente enunciativo, podemos ordenar de modo sucinto la reciente jurisprudencia relativa a planes generales y normas subsidiarias en los siguientes ámbitos.

En primer lugar, aparecen las alteraciones en el régimen del suelo, que incorporan modificaciones notables de las superficies de los ámbitos territoriales que corresponden a cada tipo de suelo y determinándose, por ello, evidentes e importantes cambios en la clasificación del suelo, lo que implica variaciones trascendentales en la calificación del mismo. Este sería el caso, por ejemplo, de la ampliación o reducción de superficie prevista para la edificación ${ }^{94} \mathrm{o}$ de las nuevas clasificaciones de suelo ${ }^{95}$.

En segundo término, por lo que respecta a los elementos que determinan la estructura general y orgánica del territorio como pueden ser los aumentos o disminuciones en la red viaria básica y en el sistema de espacios libres que posean una incidencia singular, encontrarían acomodo cuestiones tales como el desvío de una carretera del trazado inicialmente aprobado ${ }^{96}, \mathrm{o}$, la

\footnotetext{
93 También las SSTS de 13 de junio de 1995 y 13 de octubre de 1999 precitadas.

94 SSTS de 20 de noviembre de 1996, Ar. 8224, F.D. $5^{\circ}$ (P.J. YAGÜE GIL, PGOU de Pals); y 31 de enero de 2000, Ar. 581, F.D. $2^{\circ}$ (precitada).

${ }_{95}$ SSTS de 12 de noviembre de 1998, Ar. 9597 (precitada); y 27 de abril de 1999, Ar. 3094, F.D. $3^{\circ}$ (R. ENRíQUEZ SANCHO, PGOU de San Roque), relativa al aumento del suelo urbanizable programado desde $7.208 .531 \mathrm{~m}^{2}$ previstos en la aprobación inicial a $13.858 .454 \mathrm{~m}^{2}$ fijados tras la aprobación provisional; y 15 de junio de 1999, Ar. 5541, F.D. $3^{\circ}$ (M.V. Garzón Herrero, Normas Subsidiarias de La Oliva), donde de los cinco millones de metros cuadrados previstos como suelo apto para urbanizar en la aprobación provisional se pasa a un millón de metros cuadrados en la aprobación definitiva.

${ }^{96}$ STS de 12 de noviembre de 1998, Ar. 9597, F.D. $5^{\circ}$ (precitada).
} 
ubicación de un parque público en cuanto actividad discrecional, que no reglada, de la Administración ${ }^{97}$.

Y, por último, en materia de zonificación se consideran como tales «modificaciones sustanciales» las alteraciones de las determinaciones que traigan consigo importantes disminuciones en los coeficientes o edificabilidades de las zonas que se definen.

\section{4. Efectos de la omisión del trámite de información pública en los casos en que se aprecia jurisdiccionalmente la existencia de esta clase de modificaciones sustanciales}

En aquellos supuestos en los que el órgano jurisdiccional aprecia la sustancialidad de las modificaciones introducidas por la Administración urbanística entiende, asimismo, que la omisión de la apertura de un nuevo trámite de información pública supone «haber hurtado a la colectividad su derecho a participar en el procedimiento de elaboración» de los planes ${ }^{98}$. Participación que se encuentra amparada, como es sabido, además de por la legislación urbanística, por el refuerzo que suponen los arts. 9.2 y 105.a) CE y que contribuye a dotar de legitimación democrática al plan de que se trate, tal y como han reiterado el TS y los TSJ de las Comunidades Autónomas.

De modo que la reiterada omisión supone un defecto formal que determina necesariamente, por su alcance, la necesidad de realizar los actos omitidos, debiendo retrotraerse el procedimiento de elaboración de los instrumentos de planeamiento al momento en que se debió someterlos a nueva información pública, una vez introducidas las modificaciones y rectificaciones.

\section{CONCLUSIONES}

1. A pesar de que tanto la doctrina como la jurisprudencia han reiterado que la participación ciudadana en el procedimiento de confección de

\footnotetext{
97 STS de 27 de enero de 2001, Ar. 1362, F.D. $8^{\circ}$ (J. E. Peces Morate, Normas Subsidiarias de Olivares). Supuesto en el que el TS entiende que la modificación de la ubicación de un parque público efectuada por la Comunidad Autónoma tras la aprobación definitiva de las Normas Subsidiarias vulnera el principio de autonomía local constitucionalmente garantizado.

${ }^{98}$ STS de 4 de mayo de 1990, Ar. 3800, F.D. $3^{\circ}$ de la sentencia apelada aceptado por el TS (precitada).
} 
los planes corresponde al ciudadano en cuanto miembro integrante de la comunidad, sin necesidad de que sea titular de derechos o intereses específicos, de la jurisprudencia examinada se deduce que su intervención en la práctica es mínima. En efecto, son precisamente los propietarios, titulares de un interés particular, quienes desde una perspectiva cuantitativa más voluminosa participan en dicho proceso formulando alegaciones en la fase administrativa e interponiendo los correspondientes recursos en la jurisdiccional.

2. Se observa un déficit en la vigente legislación urbanística en orden a la concreción normativa de instrumentos y mecanismos a través de los cuales canalizar la participación ciudadana en el proceso al que nos venimos refiriendo, que tiene su reflejo en la jurisprudencia examinada. Desde 1956 hasta la fecha la legislación urbanística ha canalizado, casi de manera exclusiva, esa participación a través de la información pública mediante la que los ciudadanos pueden formular alegaciones y sugerencias al proyecto propuesto. Esta sacralización de un trámite del procedimiento administrativo ha supuesto que el legislador obvie otras posibilidades de intervención fuera del mismo, pero ello no es óbice para entender que la naturaleza normativa de los planes de urbanismo, a través de los cuales se imponen determinaciones vinculantes que afectan al desarrollo social, económico, cultural y geográfico de toda la comunidad, hace indispensable la existencia de nuevos cauces de participación ciudadana en su proceso de elaboración, que deben ser definidos y fijados con claridad por la legislación urbanística.

A pesar de lo anterior, tal y como hemos tenido ocasión de ver, la legislación autonómica sigue sin introducir mecanismo alguno de participación, más allá del reiterado trámite de información pública, fijando a lo sumo inconcretas y vagas fórmulas retóricas sobre el deber de fomentar o promover la participación ciudadana. Esta circunstancia pone de relieve las posibilidades que se abren para los Ayuntamientos de introducir otras técnicas participativas en el proceso de formación de los planes a través de los Reglamentos Orgánicos de Participación y de los órganos de existencia necesaria como el Consejo Social de la Ciudad.

3. Desde fecha temprana tanto la doctrina como la jurisprudencia pusieron de relieve que el fundamento constitucional de la participación ciudadana en la elaboración de los planes radicaba en los arts. 9.2 y 105.a), concepción que se ve reforzada por la cláusula interpretativa contenida en el art. 5 de la Ley Orgánica del Poder Judicial. No obstante lo anterior, parte de la doctrina ha puesto de relieve que esta concreta participación ciudadana encontraría acomodo constitucional, además de en los 
preceptos señalados, en el derecho a participar directamente en los asuntos públicos consagrado en el art. 23.1 CE. La jurisprudencia ordinaria y constitucional, por su parte, han rechazado esta tesis al entender que la reiterada participación ciudadana en el trámite de información pública del proceso de elaboración de los instrumentos urbanísticos se configura como una modalidad de participación administrativa, como el derecho a intervenir en el procedimiento administrativo y no como una manifestación de la participación política, única modalidad que encuentra acomodo en el contenido del art. 23.1 CE.

4. Diferente conclusión debemos alcanzar cuando de lo que se trata es de considerar la participación ciudadana en el proceso urbanístico mediante la celebración del instituto de la consulta popular municipal. En efecto, de acuerdo con las prescripciones deducidas de una consolidada hermenéutica del TC sobre el art. 23.1 CE, en estos supuestos nos encontraríamos en presencia de un ejemplo de participación política de la comunidad y no ante una mera intervención en un procedimiento administrativo. De modo que, a diferencia de lo que ocurre con el anterior supuesto, en el presente caso las posibles vulneraciones de la participación ciudadana en el ejercicio de sus derechos participativos a través de la consulta popular encontrarían protección en el recurso de amparo previsto en el art. $53 \mathrm{CE}$.

5. La lectura de la jurisprudencia manejada pone de relieve la escasa virtualidad práctica que presenta la intervención ciudadana en la fase preliminar de elaboración de los planes, que antecede al procedimiento administrativo de su confección. La naturaleza no vinculante del Avance, con mera eficacia interna, y la innecesariedad para la Administración de incorporar las sugerencias y propuestas ciudadanas al proyecto, ponen de manifiesto la nula consideración de la participación ciudadana en esta concreta fase.

6. A similares conclusiones se llega cuando de lo que se trata es de la exposición de los trabajos preliminares al efecto de que los ciudadanos formulen sugerencias. En este sentido, está perfectamente asumido por la jurisprudencia que la omisión de la apertura de un periodo de exposición pública con el objeto señalado no produce causa de nulidad o anulabilidad alguna, en la medida en que ese defecto formal se ve subsanado por las alegaciones que se pueden plantear tras la aprobación inicial y provisional del planeamiento. Con lo cual, se produce el efecto de limitar excesivamente las facultades de intervención de los ciudadanos.

7. Por lo que se refiere a la intervención ciudadana en el nuevo periodo de información pública que debe abrirse en los casos en que, tras las 
aprobaciones inicial, provisional y definitiva, se hubiesen introducido modificaciones sustanciales respecto del proyecto inicialmente aprobado, debemos destacar la existencia de una asentada línea jurisprudencial que ha delimitado los contornos de tal figura. En efecto, está perfectamente consolidada la noción de que estamos en presencia de un concepto jurídico indeterminado que debe ser apreciado casuísticamente, de modo que sólo una alteración del proyecto podrá considerarse como sustancial cuando reúna una serie de requisitos: que suponga un nuevo esquema de planeamiento, que altere sustancialmente las líneas básicas y estructura del plan y, en definitiva, que el modelo territorial original dibujado por éste se vea esencialmente afectado.

8. Por último, y como mecanismo determinante para clarificar la existencia o no de modificaciones de la naturaleza señalada, la jurisprudencia se remite a la existencia de los oportunos informes periciales técnicos para su acreditación. Con ello, la existencia de este tipo de informes técnicos se convierte en indispensable en aquellos supuestos en los que la naturaleza de la modificación sustancial se encuentra en una zona de incertidumbre escasamente perceptible a través de la simple comparación entre el plan propuesto y el aprobado. Y, en caso de no existir tales informes técnicos o no practicarse la correspondiente prueba, el Tribunal procederá a la desestimación de plano de la alegación formulada. 